\title{
Therapeutic Potential of Thymoquinone in Glioblastoma Treatment: Targeting Major Gliomagenesis Signaling Pathways
}

\author{
Fabliha Ahmed Chowdhury, ${ }^{1}$ Md Kamal Hossain, ${ }^{2}$ A. G. M. Mostofa, ${ }^{1}$ \\ Maruf Mohammad Akbor, ${ }^{1}$ and Muhammad Shahdaat Bin Sayeed $\mathbb{D}^{1}$ \\ ${ }^{1}$ Department of Clinical Pharmacy and Pharmacology, University of Dhaka, Dhaka 1000, Bangladesh \\ ${ }^{2}$ Department of Pharmaceutical Chemistry, University of Dhaka, Dhaka 1000, Bangladesh
}

Correspondence should be addressed to Muhammad Shahdaat Bin Sayeed; muhammad-shahdaat.bin-sayeed@fulbrightmail.org

Received 8 July 2017; Accepted 27 December 2017; Published 31 January 2018

Academic Editor: Sara Piccirillo

Copyright ( 2018 Fabliha Ahmed Chowdhury et al. This is an open access article distributed under the Creative Commons Attribution License, which permits unrestricted use, distribution, and reproduction in any medium, provided the original work is properly cited.

\begin{abstract}
Glioblastoma multiforme (GBM) is one of the most devastating brain tumors with median survival of one year and presents unique challenges to therapy because of its aggressive behavior. Current treatment strategy involves surgery, radiotherapy, immunotherapy, and adjuvant chemotherapy even though optimal management requires a multidisciplinary approach and knowledge of potential complications from both the disease and its treatment. Thymoquinone (TQ), the main bioactive component of Nigella sativa L., has exhibited anticancer effects in numerous preclinical studies. Due to its multitargeting nature, TQ interferes in a wide range of tumorigenic processes and counteract carcinogenesis, malignant growth, invasion, migration, and angiogenesis. TQ can specifically sensitize tumor cells towards conventional cancer treatments and minimize therapy-associated toxic effects in normal cells. Its potential to enter brain via nasal pathway due to volatile nature of TQ adds another advantage in overcoming blood-brain barrier. In this review, we summarized the potential role of TQ in different signaling pathways in GBM that have undergone treatment with standard therapeutic modalities or with TQ. Altogether, we suggest further comprehensive evaluation of TQ in preclinical and clinical level to delineate its implied utility as novel therapeutics to combat the challenges for the treatment of GBM.
\end{abstract}

\section{Introduction}

Glioblastoma multiforme (GBM) is a primary neuroepithelial tumor of the brain, characterized by an aggressive clinical phenotype derived from inter- and intrapatient genomic and histopathological diversity [1]. In the latest reclassification of the World Health Organization (WHO), the GBMs are listed in the group of diffuse astrocytic and oligodendroglial tumors reflecting their highly malignant behavior [2]. It constitutes more than $40 \%$ of all malignant brain tumors and approximately $54.4 \%$ of all malignant gliomas with mean age at diagnosis being 64 years and 1.5 times more common in men than women [3]. Even after the treatments by multimodal therapy that involved surgery, radiotherapy, and combined chemotherapy, GBM is nearly incurable with approximate survival rate of around 8 to 15 months after diagnosis [4]. Genomic analysis for prognostic markers of GBM has been conducted with large-scale genomic characterization. These investigations found mutations or amplifications of different signaling pathways [5-8]. The most commonly disrupted signaling cascades in GBM are pathways related to receptor tyrosine kinase (RTK), including epidermal growth factor receptor (EGFR), platelet derived growth factor receptor alpha (PDGFRA), basic fibroblast growth factor receptor 1 (FGFR-1), and insulin-like growth factor receptor (IGFR-1) [9], and nuclear factor- $\kappa \mathrm{B}(\mathrm{NF}-\kappa \mathrm{B})$ [10]. GBM has also been associated with aberration in signaling through the mitogen-activated protein kinase (RAS/MAPK), phosphatase inosine 3 kinase/protein kinase B (also known as $\mathrm{AKT} /$ mammalian target of rapamycin (PI3K/AKT/mTOR), cell cycle-regulating retinoblastoma (RB) tumor suppressor related pathways, tumor protein p53 (TP53) [11], promoter methylation of O-6-methylguanine-DNA methyltransferase (MGMT), isocitrate dehydrogenase (IDH) mutation, and 
altered expression of cyclin dependent kinase (CDK) genes [12].

The logical leap from such investigation is that targeting disrupted pathways may be an effective means of treating GBM as is the case for other type of cancers [13]. The changes in RTK, PI3K, TP53, cell cycle, neoangiogenesis, cellular metabolism, NF- $\kappa \mathrm{B}[10]$, signal transducer, and activator of transcription 3 (STAT3) [14, 15] signaling pathways have already paved the way for considering them as feasible targets in GBM $[10,16,17]$. Among the RTKs, the instance of increased gene copy number of EFGR is prevalent in GBM, which is frequently responsible for increased proliferation, transformation, adhesion, migration, and escape from apoptosis [18]. Though extensive preclinical studies with GBM have shown promising results in EGFR targeting, several clinical trials designed for therapeutic targeting of EGFR in GBM patients have failed so far [19]. The lipid kinases PI3K family are situated downstream of RTKs and with the interaction of numerous intermediary signal transduction kinases (e.g., Akt, PTEN, and mTOR), control protein translation, ribosome biosynthesis, and cell growth [20, 21]. Targeting PI3K, PTEN, and mTOR pathways have shown moderate success in combination with conventional therapy at clinical level $[17,22,23]$. Alterations in cell cycle regulatory signaling pathways, for example, CDK signaling (especially mutation of CDK4, CDK6, and CDKN2A followed by E2F1 transcription factor dysregulation), and inactivation of TP53 (either dependent or independent of MDM2 mutation), have also been extensively targeted in GBM $[8,24]$. Moreover, some studies with cell cycle inhibitors in GBM therapy have shown promise in radiosensitization as well as in the promotion of senescence and apoptosis of tumor cells $[25,26]$. Neoangiogenesis, a characteristic histopathologic feature of GBM, is in part secondary to the hypoxic tumor microenvironment that induces hypoxia-inducible factor- $1 \alpha$ (HIF-1 $\alpha$ ) followed by subsequent VEGF accumulation, RTK activation, fibroblast growth factor (FGF), PDGF, hepatocyte growth factor (HGF, also known as scatter factor), integrins, angiopoietins, and STAT3 upregulation $[14,27]$. Depriving cell of oxygen and nutrients to halt further growth is the initial justification for targeting angiogenesis. The Food and Drug Administration (FDA) of the United States of America has already approved a monoclonal antibody targeting VEGF (Bevacizumab) in GBM therapy [4] but other interventions targeting angiogenesis have not shown improvement in overall survival in GBM $[28,29]$. Clinical trials targeting multiple players in the angiogenesis pathways in GBM are underway but the outcomes are yet to be published [17]. The mutation of IDH (a component of the tricarboxylic acid cycle) occurs early in the gliomagenesis, leading towards neoenzymatic activity that converts $\alpha$-ketoglutarate to 2-hydroxyglutarate and disrupts cellular metabolism in GBM $[30,31]$ providing rationale for considering IDH as a therapeutic target and it has already prompted several clinical trials whose outcome is yet to be available [30, 32, 33]. Glioma stem cells (GSCs) represent another viable target in GBM treatment due to their important role in mediating therapeutic resistance [34]. A number of other novel targets, such as poly-ADP ribose polymerase (PARP) (DNA repair protein), BRAF (a protein kinase that mediates MAP kinase signaling), bone-marrow Xlinked kinase (BMX), Bruton's tyrosine kinase, and gammasecretase, are now under investigation for GBM treatment at preclinical level[17, 35-37]. However, chemotherapeutic drugs still remains the mainstay in glioblastoma treatment. At present, the chemotherapeutic drugs for GBM approved by FDA act as alkylating agents (Temozolomide (TMZ) and Nitrosourea) $[4,38]$ which are not sufficient to combat GBM. Based on this situation, there have always been a need to find new therapeutics for GBM.

Thymoquinone (2-methyl-5-isopropyl-1, 4-benzoquinone; TQ) is the principle active ingredient of the volatile oil of black cumin or black seed (Nigella sativa L. (NS)) (family Ranunculaceae) [39]. People in different societies used NS as condiment and different traditional medicinal system such as Ayurvedic and Unani systems consider NS for the treatment of various maladies [40-43]. The pharmacological investigations of TQ [44] are almost as old as its isolation from NS in 1963 by El-Dakhakhny [45]. Since then, numerous preclinical studies have been performed including those to determine the anticancer effects of TQ. The molecular mechanism of through what TQ shows selective cytotoxicity for human cancer cells is widely reported [46]. Studies have shown that TQ causes selective cancer cell death and possess tumor growth inhibitory activities in addition to its role in interference with other tumorigenic processes such as angiogenesis, invasion, and metastasis $[47,48]$. TQ is involved in tumorigenesis or development of drug resistance [49] as well as in the sensitization of cancer cells to chemotherapeutic agents and radiation therapy through the resistance mechanisms $[31,50]$. The result of a registered investigation for studying the role of NS in a precancerous disease, actinic keratosis (AK), is yet to be reported (ClinicalTrials.gov Identifier: NCT01735097; website: https://clinicaltrials.gov/ct2/show/record/NCT01735097 accessed on 26 June, 2017). Hence, the usefulness of TQ in cancers including GBM is now more than a speculation and it can target different hallmarks [51] of GBM.

There are several reviews on GBM [52], its pathology $[53,54]$, possible therapeutic targets $[17,55,56]$, and current challenges in its therapies [54]. The treatment with TQ alone has shown antitumor efficacy in several in vitro and in vivo studies $[57,58]$ and also as in adjuvant therapy either to prevent carcinogenesis [59] or to potentiate the efficiency of conventional therapeutic modalities [60]. However, there is no systemic compilation of the potential role of TQ as a therapeutic agent or as an adjuvant agent for the treatment or the prevention of GBM or an agent for slowing the progress of GBM. In this review, we have compiled the potential role of TQ in GBM therapeutics focusing on the major gliomagenesis signaling pathways.

\section{Potential Role of TQ in Modulating Proliferative and Migratory Signaling Pathways of Glioblastoma}

Two of the most important signaling cascades frequently deregulated in GBM are the PI3K/Akt/mTOR and Ras/Raf/ 


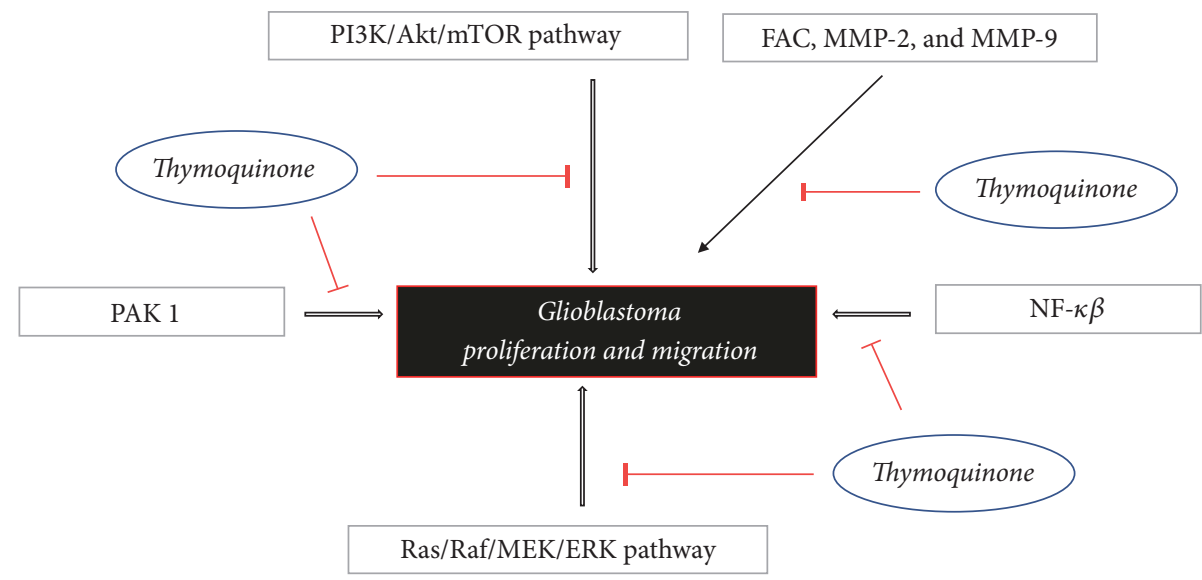

FIGURE 1: Signaling pathways of proliferation in glioblastoma targeted by Thymoquinone (NF- $\kappa \beta$ : nuclear factor- $\kappa \beta$; FAC: Focal Adhesion Molecule; MMP-2: Matrix Metalloproteinase-2; MMP-9: Matrix Metalloproteinase-9; PAK1: p21 protein (Cdc42/Rac) activated kinase 1; PI3K/AKT/mTOR: phosphatase inosine 3 kinase/protein kinase B (also known as AKT)/mammalian target of rapamycin. Ras/Raf/MEK/ERK: a chain of proteins in the cell that communicates a signal from a receptor on the surface of the cell to the DNA in the nucleus of the cell; Ras: a type of small GTP-binding protein; Raf: Raf kinase family of serine/threonine-specific protein kinases; MEK: a protein kinase; ERK: a member of the mitogen-activated protein kinase superfamily). Aside from FAC, MMP-2, and MMP-9, other signaling pathways primarily affect glioblastoma proliferation.

MEK/ERK pathways that promote cell growth and proliferation $[61,62]$. In addition, the dysregulation of RTK, non-RTK (c-src activity), growth factors (e.g., PDGF, FGF, TGF, and IGF-1), GTPase activating protein (G protein), serine/threonine-specific protein kinase (STK), and NF- $\kappa \mathrm{B}$ activity differentially contributes to GBM proliferation [6366]. Studies have shown that aberrant constitutive activation of $\mathrm{NF}-\kappa \mathrm{B}$, in response to PDGF overexpression/PI3K signaling/PTEN inactivation, can promote GBM proliferation through inappropriate activation of regulatory genes that control cell proliferation and cell survival [67]. Nonreceptor tyrosine kinase, Focal Adhesion Kinase (FAC), is associated with increased rates of both migration and invasion in GBM [68]. The FAC signaling regulates cell adhesion and motility by relaying extracellular matrix (ECM) signals to ERK signaling and secreting matrix metalloproteinase- (MMP-) 2 and MMP-9 [69-71].

No study has been conducted yet regarding the role of TQ in modulating the proliferative signaling pathways in GBM but studies in other type of cancer have demonstrated that TQ upregulates PTEN signaling [72, 73], interferes with PI3K/Akt signaling and promotes G(1) arrest, downregulates $\mathrm{PI} 3 \mathrm{~K} / \mathrm{Akt}$ and NF- $\kappa \mathrm{B}$ and their regulated gene products, such as p-AKT, p65, XIAP, Bcl-2, COX-2, and VEGF, and attenuates mTOR activity [73-78], providing the strong rationale that TQ might play a crucial role in inhibiting $\mathrm{PI} 3 \mathrm{~K} / \mathrm{Akt} / \mathrm{mTOR}$ signaling pathways, NF- $\kappa \mathrm{B}$, resulting in inhibiting proliferative signaling pathways of GBM. Studies in colorectal cancer have demonstrated that TQ inhibits the Ras/Raf/MEK/ERK signaling and disrupts its prosurvival function, especially affecting the kinase domain of the p21 protein (Cdc42/Rac) activated kinase 1 (PAK1), consequently disturbing its interaction with pPAK(Thr423) [79]. Phosphorylated Pak1 level in the cytoplasm has also been reported to correlate with shorter survival time in patients with GBM
[80]. Multiple studies have reported that TQ downregulates FAC and reduces the secretion of MMP-2 and MMP-9 and thereby reduces GBM cells migration, adhesion, and invasion $[81,82]$. Therefore, there is a strong possibility of TQ to provide therapeutic benefits for the treatment of GBM (Figure 1). However, we propose further investigation in this regard.

\section{Cytotoxic and Antiapoptotic Potential of TQ against Glioblastoma}

TQ may exhibit glioma cell-specific cytotoxic effects [83] by influencing cell cycle, DNA structure and synthesis, structural proteins like tubulin, apoptotic mechanism, and ROS generation (Figure 2). It has been reported that TQ can interfere in normal cell cycle progression and thereby inhibit GBM growth [84]. Several studies have shown that TQ has the capacity to cause cell cycle arrest at different phases $[46,85]$. TQ treatment can alter the expression of multiple cell cycle regulatory proteins, such as cyclin D1, cyclin E, and the CDK inhibitor p27 [74], and induce apoptosis (accumulation of sub-G1 population) through caspase activation and PARP cleavage [86].

TQ influences both p53-dependent and p53 independent pathways for apoptosis [72, 87]. TQ augments the proapoptotic and reduces the antiapoptotic regulatory proteins. TQ induced apoptosis involves changes in mitochondrial membrane potential, activation of caspases and PARP cleavage [88], increase in the $\mathrm{Bax} / \mathrm{Bcl}-2$ ratio via downregulating $\mathrm{Bcl}-2$ and upregulating Bax level [88], raise in level of cytochrome $c$ and caspase-3, along with suppressed expression of $\mathrm{Bcl}-\mathrm{xL}$ and survivin [74], degradation of alpha and beta tubulin, and increase in p73 expression leading to apoptosis in cancer cells [87]. 


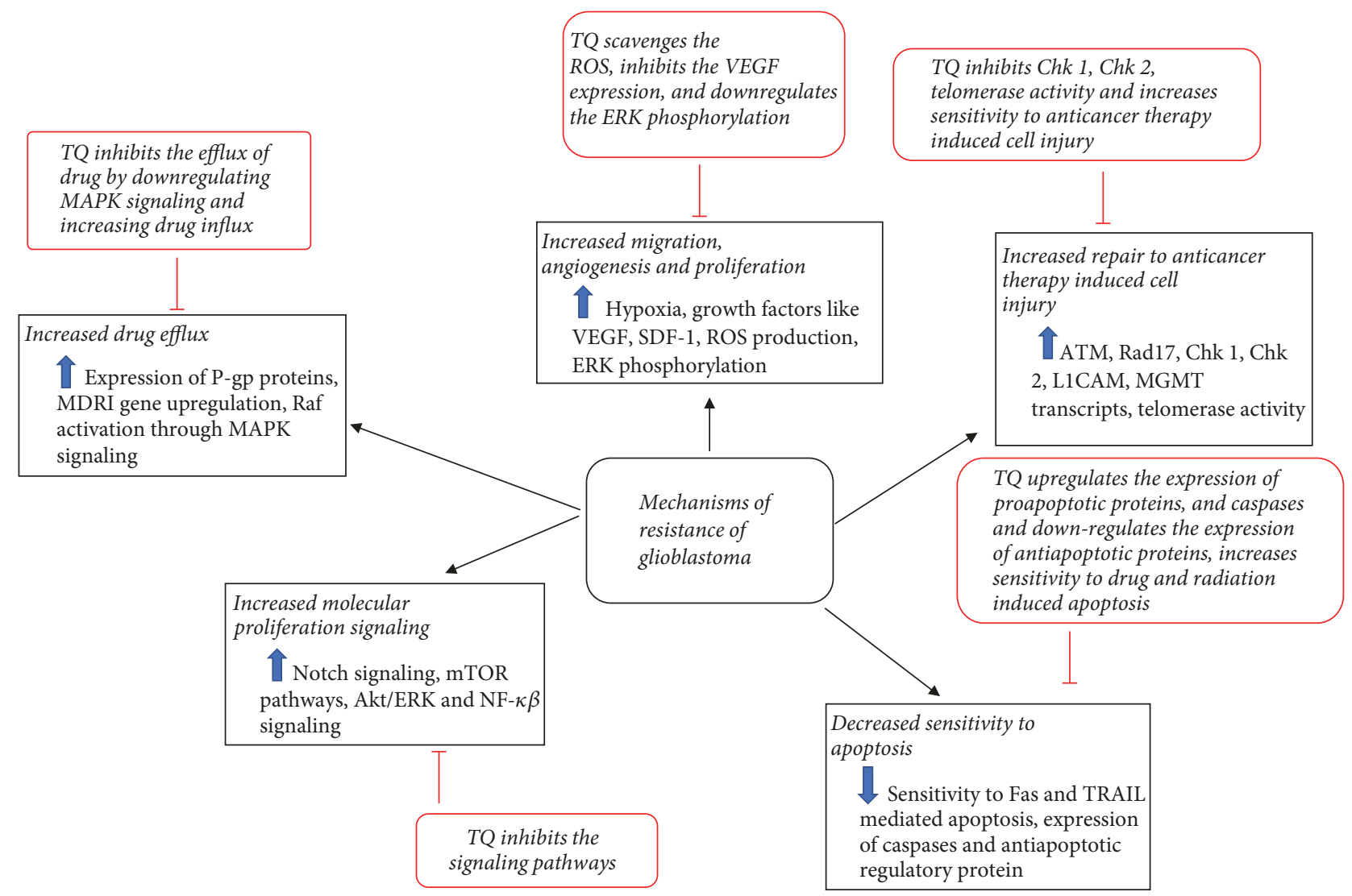

FIgURE 2: Antiapoptotic and chemosensitization potential of Thymoquinone.

TQ is hypothesized to act as an antoxidant at lower concentrations and a prooxidant at higher concentrations depending on its environment [89]. In tumor cells specifically, TQ generates ROS production that leads to reduced expression of prosurvival genes, loss of mitochondrial potential, and structural changes in proapoptotic changes causing caspase-dependent apoptosis in the cells [90]. A recent study on human colon cancer cells demonstrated elevated level of ROS generation and simultaneous DNA damage when treated with a combination of TQ and artemisinin [91]. TQ mainly attenuates its proapoptotic and oxidative potential through suppressing the NF- $\kappa$ B pathway [92]. This simultaneously inhibits the activation of IKBA kinase, IKBA phosphorylation, IKBA degradation, p65 phosphorylation, and p65 nuclear translocation. The expressions of NF- $\kappa \mathrm{B}-$ regulated antiapoptotic (IAP1, IAP2, XIAP Bcl-2, Bcl-xL, and survivin), proliferative (cyclin D1, cyclooxygenase-2, and c-Myc), and angiogenic (matrix metalloproteinase- 9 and VEGF) gene products are also downregulated by TQ [92, 93].

TQ affects the DNA structure by targeting the copper in the chromatin, which is associated closely with the base guanine [89]. In normal cells, DNA damage will initiate repair by p53 mediated p21 triggered growth inhibitory effects. However, in GBM cells, TQ induced DNA damage directly causes cell death [94]. DNA-dependent protein kinase (DNA-PKcs) is necessary for repairing breaks in DNA double strand in order to maintain genomic integrity [95]. However, despite the prominent cell damage in DNA-PKcs deficient GBM cells, they are found to be less sensitive to TQ induced cytotoxicity as compared to DNA-PKcs proficient GBM cells. The significant cell death seen in DNA-PKcs proficient GBM cells justifies the theory that these cells are attacked by TQ and that DNA-PKcs activation is essential for cellular death in GBM [96].

Telomere attrition, due to inhibition of telomerase by TQ through the formation of G-quadruplex DNA stabilizer, subsequently leads to rapid DNA damage which can eventually induce apoptosis in cancer cells specifically [97]. In a recent GBM cell line study, TQ has shown to reduce telomerase activity and cause significant DNA damage [94] in addition to its inhibitory role in DNA synthesis in cancer cells affecting cellular proliferation and viability [58].

\section{Targeting Chemosensitization and Drug Resistance Mechanisms of Glioblastoma by TQ}

GBM possesses very complex resistance mechanisms associated with cell cycle and DNA repair, apoptosis, drug efflux, growth factors, and cellular maintenance pathways [98, 99]. Evidently, TQ can significantly affect the drug resistance of GBM through inhibition of its resistance strategies and induce chemosensitization, by acting as an adjuvant to a therapy via affecting variety of signaling pathways (Figure 2). 
GBM stem cells are seen to demonstrate an increased sense of repair to injury after radiotherapy, due to enhanced activation of ATM, Rad17, Chk1, and Chk2 [100]. Another cell surface protein molecule known as L1CAM, which is expressed nearly twice in resistant GBM cells, amplifies the DNA repair capacity through adhesion [101]. There is a 32 -fold increase in the level of the repair enzyme MGMT transcripts in GBM cells which acts as a means of resistance against the anticancer alkylating agents [102]. TQ is seen to reduce the level of Chk1 (cell cycle checkpoint kinase) in p53 ${ }^{-/}$HCT116 colorectal carcinoma cells. As a result this increases the caspase 3 activity leading to DNA damage and apoptosis, decreasing the extent of DNA repair [103].

GBM cells have decreased sensitivity to both Fasmediated and TRAIL-mediated apoptosis $[104,105]$. The reduced presence of caspase-8 [106] and increased expression of $\mathrm{Bcl}-2$, an antiapoptotic regulatory protein [107], are the contributory causes behind the resistance. In a study with a model of colorectal tumorigenesis, it was observed that TQ increases the chemosensitivity of 5-fluorouracil (5-FU) by suppressing the NF- $\kappa \mathrm{B}$ pathway and upregulating antitumorigenic proteins [108]. Telomerase and DNA-PKcs deficiency play huge role in cellular resistance to apoptosis of GBM cells $[94,109]$. However, GBM cells also carry specific mutations and miRNAs that inactivate the apoptosis [107] for what further investigations are required regarding the relevance of TQ treatment.

The higher apoptotic index in GBM is supported by their higher proliferation, presence of hypoxic region, angiogenesis, and migration [107]. The cancer cells facing hypoxia tend to remain inactive, do not proliferate, and create resistance to the cytotoxic anticancer drugs which cannot reach those [110, 111]. Extensive research has elucidated the fact that cancer cells express higher level of hypoxia-inducible factors [112]. Hypoxia induces the production of ROS that favors the tumor survival, progression, and adaptation [113]. TQ acts as an antioxidant in this case and scavenges the ROS including the superoxide anion, hydroxyl radical, and singlet molecular oxygen [114]. It has the capacity to readily travel across the blood-brain barriers (BBB) and reach the subcellular compartments [115], thus reaching the inner hypoxic regions of the tumor in the brain.

The mTOR is a protein kinase that ensures supply of nutrients to tumor cells and inhibits apoptosis and autophagy. This kinase is upregulated in tumors causing enhanced growth and proliferation, through Akt signaling [20]. The Notch signaling is another pathway found enhanced in tumor cells, which is necessary for the activation of transcription factors required for regulation of nervous system. Its activity is mediated by an enzyme gamma-secretase that stimulates its active signaling [116]. However, gamma-secretase activity can be inhibited by reducing Akt activity [117]. Thus both mTOR and Notch pathways involve Akt/ERK signaling that is downregulated by TQ [77]. TQ was found to chemosensitize gemcitabine against cancer cells in inducing apoptosis by inhibition of Akt/mTOR/S6 signaling pathways and reduced expression of antiapoptotic proteins [118], providing a strong rationale for the potentiating role of TQ with gemcitabine in GBM therapy [119].

Active efflux of anticancer drugs out of the cancer cell by ATP-binding cassette $(\mathrm{ABC})$ transporters is one of the major criteria of resistant glioblastoma cells [120]. Overexpression of P-glycoprotein (P-gp), an ABC transporter, occurs because of the upregulation of the MDR1 gene, which is induced by mutation, activation of Raf, anticancer drugs, and DNA damaging agents [121]. Although TQ cannot prevent drug efflux directly, but it can indirectly help through inhibition of Raf activation, by downregulating MAPK [122], which will consequently downregulate the MDR1 gene expression, thus preventing the overexpression of P-gp. TMZ is currently the most widely used chemotherapy for GBM [123]. TQ is seen to give synergistic effect with TMZ in inducing apoptosis and cell growth inhibition in GBM cells [124]. As TQ is a small lipophilic molecule and, as mentioned earlier, can easily cross the BBB, it can help the chemotherapeutic agent in reaching the tumor while being used as an adjuvant and also by preventing the drug efflux indirectly, creating chemosensitization.

\section{Potential Role of TQ to Mediate Neuroinflammation and Immunotherapy in Glioblastoma}

GBM plays role in generating immunosuppressive microenvironment by producing different immunosuppressive cytokines including IL-6, IL-10, and TGF- $\beta$ as well as tumor aggravating IL-1 and basic fibroblast growth factor (bEGF) resulting in neuroinflammation [125-127]. These cytokines promote antitumor immune response by inhibiting effector $\mathrm{T}$ cell response and activating regulatory $\mathrm{T}$ cell (Tregs) expression $[128,129]$. In addition to cytokines, macrophage and myeloid derived suppressor cells also infiltrate into the GBM microenvironment and cause inhibition of antitumor immune response [130,131]. Also, immunosuppressive checkpoints including CTLA-4, PD-1, LAG-3, and TIM-3 is known to have potential role in escaping immune environment of GBM [132].

Successful immunotherapeutic approach depends on its targeting of GBM cells specific antigen and its ability to kill tumor cells [129]. There are a number of antigens found that are glioma associated such as EPhA2, HER-2, gp 100, and TRP-2 [133-135]. However, EGFR found in around 25 percent of GBM patients is the most targeted one to the researchers. Peptide based vaccines for GBM usually target antigens such as EGFRvIII, survivin, and heat shock protein and currently couple of vaccines are in various stages of clinical trial including CDX-100 and M57-KLH [136]. Studies have provided evidence that TQ has potential to downregulate tumor associated antigen [137] and therefore hold promise to possess therapeutic benefit in inhibiting GBM antigen expression but further investigations are required in this regard.

Dendritic cells (DCs) vaccination is an important avenue of immunotherapy that utilizes DCs to make a bridge between innate and adaptive immune responses $[138,139]$. 


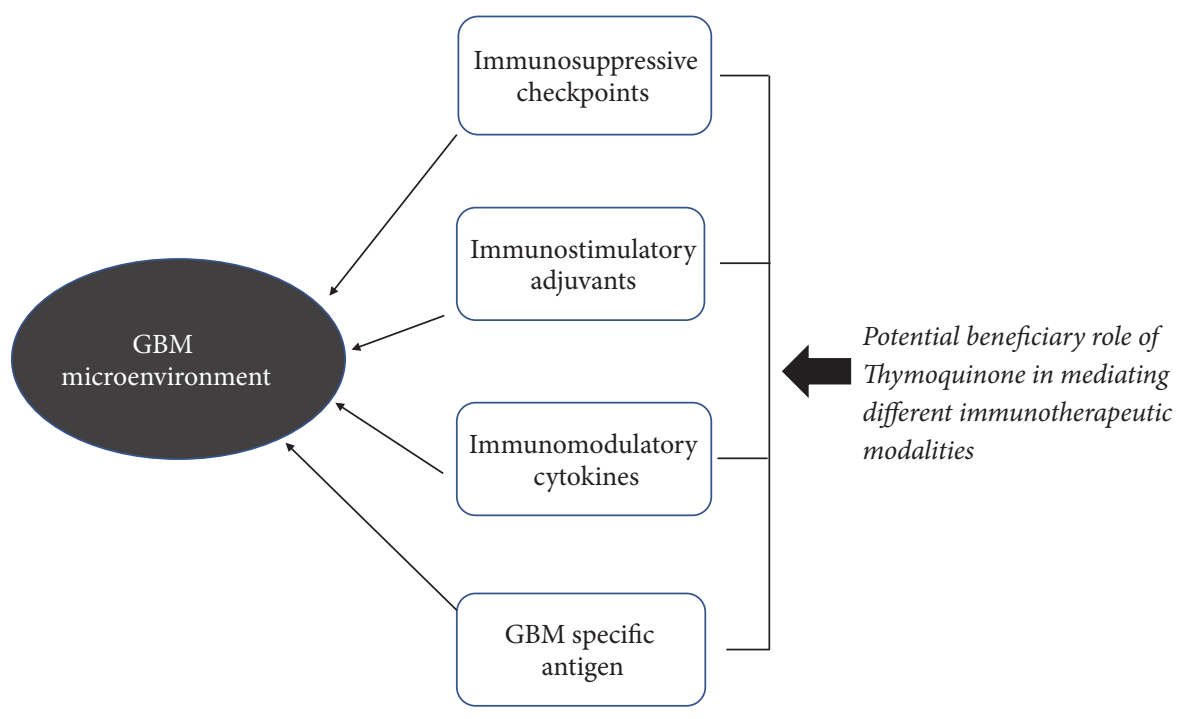

FIgURE 3: Potential beneficiary role of Thymoquinone in mediating different immunotherapeutic modalities.

Since DCs cannot process antigen effectively in immunosuppressive microenvironment, they are being cultured outside of patient body with exposing to antigen. Reinvigorated DCs are then inserted back to patient body which then activate $\mathrm{T}$ cells like CD4, CD8, and natural killer cells [129, 140]. Even though the DC based vaccine appears to be comparatively safe, its efficacy and clinical output are still limited. However, positive immune response among GBM patients were found when they are treated with DCs pulsed with different antigens with different degree of success [141, 142]. Studies have demonstrated that TQ compromises inflammation induced DC maturation, an important step towards antigen presentation to T cell and for effective antitumor immunity [143], and blunts inflammation induced cytokine release and migration of DCs [144], providing avenue for the further investigation regarding the role of TQ in DC cell based GBM therapy.

Immune stimulatory adjuvant are thought to initiate innate immune response through activation of toll-like receptors (TLRs) and pattern recognition receptors (PRRs), necessary components for maintaining the balance between both cellular and humoral immune response [145]. Commonly used adjuvants include CpG oligonucleotides, poly-ICLC, and tetanus toxoid. In two separate phase II clinical trials among GBM patients, it has been found out that treatment with poly-ICLC was well tolerated and improves the efficacy of radiotherapy [146, 147]. Studies have shown that TLR mediated by Neul sialidase activation [148] which is mediated by TQ provides avenue for further investigation regarding the role of TQ in the TLR mediated beneficial effect in GBM immune adjuvant therapy [149].

Immunomodulatory cytokines play important role in GBM and other cancer types. IL-6 is recognized for stimulating tumor growth in GBM patients, whereas IL-10 is known for inhibiting IFN- $\gamma$ and TNF- $\alpha$ production $[150,151]$. IL-10 is also responsible for decreased expression of MHC class II and inducing anergy in T cells $[152,153]$. TGF- $\beta$ is known to mediate immunosuppression by regulating $\mathrm{T}$ cell proliferation, IL2 production, and $\mathrm{NK}$ cell activity and promoting regulatory
T cells (Tregs) activity $[154,155]$. A phase I clinical study among malignant glioma patients revealed that inhibiting Tregs by basiliximab, a monoclonal antibody to IL-2 receptor, generates improved immune response $[56,156]$. TQ is known to inhibit the ability of TNF- $\alpha$ to induce IL- 6 production in a different disease group [157]. This implies that further investigation is necessary to find out the impact of TQ on immunomodulatory cytokines in GBM patients.

TQ possesses significant antineuroinflammatory effect [158] and improves the anticancer activity of other therapeutic agent through either inhibition of autophagy or apoptotic cell death of GBM cell line [124, 159]. We hypothesize that TQ might help overcome those immunosuppressive mechanisms [160-162] in GBM immunotherapy and therefore further investigations are required for the potential role of TQ in different immunotherapeutic modules including the potential synergistic role of TQ on the therapeutic efficacy of immune checkpoints (CTLA-4 and PD-1) blockers for the treatment of GBM (Figure 3).

\section{Potential Role of TQ to Inhibit GBM Stem-Like Cells from Acquiring a Mature Postmitotic Phenotype and Decrease Survival}

It has been widely suggested that the subpopulations of tumor-initiating or stem-like cells are one of the primary factors causing GBM recurrence and resistance to treatment $[100,163]$. It has been observed that GBM stem-like cells have higher levels of nuclear p65 and NF- $\kappa \mathrm{B}$-dependent gene expression than regular glioma cells [164]. Studies have suggested that NF- $\kappa \mathrm{B}$ signaling has been linked to the proliferation, migration, and differentiation of neural stem cells [165] which is considered as one of the potential cell of origin of brain tumors. One of the subunits of $N F-\kappa B$, RelB, is highly expressed in mesenchymal GBM and studies have shown RelB regulates expression of Olig2 [166], a 
critical factor in normal and tumorigenic stem-like cell proliferation. Studies have shown that TQ interferes with the expression of RelB [167] and thus shows potential to interfere with tumorigenic stem-like cell proliferation. Studies have suggested that activation of $\mathrm{NF} \kappa \mathrm{B}$ may keep differentiating glioblastoma-initiating cells (GICs) from acquiring a mature postmitotic phenotype, thus allowing cell proliferation and support the rationale for therapeutic strategies aimed to promote premature senescence of differentiating GICs by blocking key factors within the $\mathrm{NF} \kappa \mathrm{B}$ pathway [168]. It is well established that TQ blocks NF- $\kappa$ B from multiple molecular pathways but further investigation is suggested for the role of TQ in promoting senescence of GICs. Studies have shown that STAT3 is upregulated in GBM-derived brain tumor stem cells (BTSCs) [169] and inhibition of STAT3 either by pharmacological agent or by gene knockdown resulted in reduced BTSC survival regardless of endogenous MGMT promoter methylation or EGFR, PTEN, and TP53 mutational status [170]. TQ has shown to suppress STAT3 in myeloma, gastric, and colon cancer $[86,171,172]$ and, therefore, we hypothesize that TQ would be inhibiting BTSCs but further investigations are warranted. We also propose more investigations regarding the role of TQ in preventing treatment resistance mediated from GBM stem-like cells in conventional GBM therapy.

\section{Potential Beneficiary Role of TQ in Surgery and Ionization Radiation Therapy in Glioblastoma}

Surgery and radiation therapy are two major modules for GBM treatment. The underlying molecular mechanisms that are overactivated or inactivated nearby the surgical area of GBM is still poorly understood [173] which partly contribute to the GBM reappearance, aggressive proliferation, and induction of metastatic potential in the microscopic tumors that are not eliminated through tumor resection $[174,175]$. Many mitogenic and proangiogenic factors, such as TGF- $\beta$, FGF, VEGF, EGF-like growth factors, and endostatin, were found in the wound fluids that stimulate cancer cell proliferation and neoangiogenesis during postsurgery wound healing period [176-178]. Studies have shown that TQ attenuates tumorigenic signaling, including those mediated by TGF- $\beta$, VEGF, EGF, and several other promitogenic, angiogenic, and metastatic factors, with the inhibition of cancer cell growth, migration, and invasion [48, 179-182]. Studies have shown that TQ counteracts the trauma-induced chemotaxis of circulating malignant cells and their epithelial to mesenchymal transition (EMT) $[48,181,183]$ and interferes in the activation of nuclear factor erythroid-related factor-2 (Nrf-2), $\mathrm{NF}-\kappa \mathrm{B}$, and STAT-3 that are responsible for the transcriptional activation of genes encoding proteins involved in cell proliferation, angiogenesis, and metastasis [50, 184]. Thus, TQ demonstrates very strong rationale for possible beneficial agent as a preoperative and/or postoperative neoadjuvant in GBM treatment.

Radiation therapy for GBM has been used in conjunction with surgery for over 35 years [185] and almost 50\% of all cancer patients receive this therapy in one form or another during their course of illness [186]. It causes cell to undergo apoptosis due to double-stranded breaks via inducing DNA damage. Even though it is an effective therapeutics, it is restricted by some inherent limitations, such as the detrimental effect to surrounding normal tissues and the stimulation of cancer cells adaptive responses to counteract the damage process. Cancer cells that survived after initial cycles acquire resistance through multiple cellular mechanisms such as activation of NF- $\kappa \mathrm{B}, \mathrm{PI} 3 \mathrm{~K}, \mathrm{Akt}$, and mTOR [187] but the resistance to radiotherapy in GBM is primarily attributed to EGFRvIII. This mutation confers an EGF ligand-independent dimerization of the EGF receptor resulting in constitutive activation of the EGF/EGFR signaling pathway [188, 189] and thus cellular resistance to radiation therapy by upregulating the DNA double-stranded break repair machinery [190]. Therefore, EGFRvIII inhibitors are readily rationalized to possess increased overall GBM sensitivity to radiation therapy. Studies have found that EGFRvIII mutant GBM cell proliferation is more sensitive to TQ than wild-type GBM cells. It was also found that TQ inhibits autophagic flux and induces caspase-independent apoptotic cell death of the EGFRvIII mutant GBM cells to the similar extent of the wild-type GBM cells [115]. TQ might enhance radiation therapeutic benefit by enhancing the cytotoxic efficacy of radiation through modulation of cell cycle and apoptosis [31], preventing the radiation-induced metastatic progression through restoration of TGF- $\beta$ [179] and activation of several signal transduction pathways including PI3K-Akt-mTOR $[49,187,191,192]$ or by rescuing T-lymphocytes from gamma irradiation-induced apoptosis [193]. Even though free radical scavenging ability and antioxidant properties of TQ are primarily considered for the mechanistic explanations of TQ mediated beneficial effect [192] but it is obvious that other mechanisms are involved and thus we propose further extensive investigations.

\section{Summary and Future Perspective}

GBM is one of the least understood diseases. Highly heterogeneous cell populations and complex pathogenesis add further complexities for effective therapeutic agent developments. The presence of $\mathrm{BBB}$ adds another layer of complexity in combating this disease. Though considerable advancements have been accomplished in GBM molecular pathogenesis and thereby in treatment strategies, the overall survival rates remain poor. Targeting a particular molecule or signaling pathway, involved in one of the singular aspects of the multistep complex tumorigenesis processes, has recently been deemed as extravagant attempt to curtail malignant progression. Due to the inherent heterogeneous nature, GBM can always evade a particular therapeutic modality and continue to survive on alternative pathways followed by recurrence of tumor at a far more aggressive form. Therefore, the paradigm in cancer treatment strategy is now shifting from targeted therapy to combination or multitargeted approaches or targeting cancer with modalities that affect multiple signaling pathways. 
As a multitargeting therapeutic substance, TQ has been investigated in numerous disease models along with different types of cancer in vivo and in vitro models including GBM. Studies have focused on various signaling pathways providing evidence for its potential use in the GBM therapeutics. The prominent GBM signaling pathways includes the role of TQ in interfering in the phosphorylation and subsequent activation of several upstream tyrosine kinases (e.g., MAPK, Akt, mTOR, and PIP3) that are involved in tumor cell proliferation signaling pathways $[49,180]$. Transcriptional factors (e.g., Nrf2, NF- $\kappa$ B, and STAT-3) that are considered as key players in various oncogenesis process are other crucial molecular targets of TQ $[49,57,84]$. It has been suggested by multiple studies that, by regulating the activation of these transcription factors, TQ might counteract different tumorigenic processes including inflammation, cell proliferation, cell survival, angiogenesis, cell invasions, and metastasis. Furthermore, TQ shows chemopreventive properties by downregulating carcinogen metabolizing enzymes (e.g., CYP 1A2 and CYP 3A4), upregulating cytoprotective enzymes (e.g., glutathione S-transferase, superoxide dismutase, and oxidoreductase), attenuated production of proinflammatory mediators (e.g., cytokines, chemokines, and prostaglandins) [49]. Among different signaling pathways several are significant in the context of GBM therapy with TQ; the JAK/STAT and NF- $\kappa \mathrm{B}$ are getting increasing attention in the context of GBM. The JAK/STAT signaling in GBM consists of four JAKs (JAKs1-3 and TYK2) and seven STATs (STATs1-4, 5a, 5 b, and 6) [194] but STAT3 is generally considered as the most eminent among cancers [195]. In GBM, protein kinase $\mathrm{C} \varepsilon$ has been shown to drive serine phosphorylation of STAT3 in a RAK/MEK/ERK-dependent fashion, and this modification of STAT3 enhances the invasive capacity and apoptosis resistance of GBM $[196,197]$. STAT3 upregulation, hyperactivation, and nuclear accumulation is a well-known feature of GBM [198]. Studies have shown that TQ inhibits proliferation in gastric cancer via STAT3 pathway in vivo and in vitro [171] alone and also in combination with other drugs in breast cancer [199]. We propose further investigation for the role of TQ in GBM in JAK/STAT3 pathways. Further investigations are also required whether TQ affect specific parts of NF- $\kappa \mathrm{B}$ such as $\mathrm{I} \kappa \mathrm{K}$ complex that is involved in the regulating $\mathrm{NF}-\kappa \mathrm{B}$ activation or regulate $\mathrm{NF}-\kappa \mathrm{B}$ signaling in a more selective manner by specifically interacting with NF$\kappa \mathrm{B}$ dimers or whether TQ blocks NF- $\kappa \mathrm{B}$ by directly targeting the subunits (p65 and p50) themselves. This is of particular interest because of the fact that one available drug, TMZ, has opposite effects in the subunits [200]. Previous study in GBM cells has shown that Ikk inhibitors decrease proliferation and increase apoptosis directly [201] or via inhibiting nuclear p65 translocation [202]. Study regarding the effects of TQ on proteasomes is also suggested since inhibitors of proteasomes has shown to have beneficiary effects on GBM [203] but whether such effects are mediated by TQ has not been investigated.

TQ induces selective and time-dependent proteasome inhibition, both in isolated enzymes and in GBM cells, suggesting that this inhibition leads to intracellular increases in the levels of apoptotic proteins such as p53 and Bax, and may be linked to the onset of apoptotic events [204]. Therefore, we propose further investigations on TQ as its potential application as an adjuvant in the treatment of cancer and other diseases. In the clinical settings, no such study has been conducted with TQ for the treatment of GBM but one general conclusion is that improved understanding of the molecular mechanism by which GBM is regulated is a strategy that can make a significant impact in the successful management of GBM.

Interestingly, even the lower efficacy [205] and poor bioavailability [206, 207] of TQ are the primary bottleneck of TQ, its volatile nature [208] provides opportunity to be exploited for use in novel drug delivery strategy via intranasal pathway to brain due to unique connection provided by the olfactory and/or trigeminal nerve system present between the olfactory epithelium and the central nervous system. Such delivery system provides opportunity to bypass both the BBB and hepatic first-pass metabolism [209].

It is evident that TQ is multitargeting in its nature but majority of the signaling pathways in the GBM pathogenic context is yet to be explored. Due to its lower efficacy and systemic bioavailability, we propose further investigation on its role as adjuvant therapy with other chemotherapeutic courses. Further investigation could also be conducted for its more efficacious analogues and formulating those into different delivery systems to cross BBB in GBM treatment along with determination of their pharmacokinetic behavior, efficacy, and toxicity. To better understand these differential cellular effects of TQ, more in vitro, in vivo, and in silico studies could be conducted at both proteomic and genomic level. Findings from such studies will enable us to devise clinically effective combination therapeutics where TQ or its derivatives can potentiate the antitumorigenic potential of various conventional and established GBM therapeutic courses.

\section{Conflicts of Interest}

The authors declare that they have no conflicts of interest.

\section{Authors' Contributions}

Muhammad Shahdaat Bin Sayeed and A. G. M. Mostofa conceived the idea, Fabliha Ahmed Chowdhury and Muhammad Shahdaat Bin Sayeed wrote the major sections of the manuscript, Md Kamal Hossain wrote Section 5, and Maruf Mohammad Akbor provided critical insights.

\section{References}

[1] W. Szopa, T. A. Burley, G. Kramer-Marek, and W. Kaspera, "Diagnostic and therapeutic biomarkers in glioblastoma: current status and future perspectives," BioMed Research International, vol. 2017, Article ID 8013575, 13 pages, 2017.

[2] D. N. Louis, A. Perry, G. Reifenberger et al., "The 2016 world health organization classification of tumors of the central nervous system: a summary," Acta Neuropathologica, vol. 131, no. 6, pp. 803-820, 2016.

[3] Q. T. Ostrom, H. Gittleman, P. Farah et al., "CBTRUS statistical report: primary brain and central nervous system tumors 
diagnosed in the United States in 2006-2010," Neuro-Oncology, vol. 15, supplement 2, pp. iil-ii56, 2013.

[4] K. Anjum, B. I. Shagufta, S. Q. Abbas et al., "Current status and future therapeutic perspectives of glioblastoma multiforme (GBM) therapy: A review," Biomedicine \& Pharmacotherapy, vol. 92, pp. 681-689, 2017.

[5] A. Sottoriva, I. Spiteri, S. G. M. Piccirillo et al., "Intratumor heterogeneity in human glioblastoma reflects cancer evolutionary dynamics," Proceedings of the National Acadamy of Sciences of the United States of America, vol. 110, no. 10, pp. 4009-4014, 2013.

[6] T. R. Jue and K. L. McDonald, "The challenges associated with molecular targeted therapies for glioblastoma," Journal of Neuro-Oncology, vol. 127, no. 3, pp. 427-434, 2016.

[7] Cancer Genome Atlas Research Network, "Comprehensive genomic characterization defines human glioblastoma genes and core pathways," Nature, vol. 455, no. 7216, pp. 1061-1068, 2008.

[8] D. W. Parsons, "An integrated genomic analysis of human glioblastoma multiforme," Science, vol. 321, no. 5897, pp. 18071812, 2008.

[9] H. Ohgaki and P. Kleihues, "Genetic alterations and signaling pathways in the evolution of gliomas," Cancer Science, vol. 100, no. 12, pp. 2235-2241, 2009.

[10] K. E. Cahill, R. A. Morshed, and B. Yamini, "Nuclear factor- $\kappa$ B in glioblastoma: Insights into regulators and targeted therapy," Neuro-Oncology, vol. 18, no. 3, pp. 329-339, 2016.

[11] C. W. Brennan, R. G. Verhaak, and A. McKenna, "The somatic genomic landscape of glioblastoma," Cell, vol. 155, no. 2, pp. 462-477, 2013.

[12] J. T. Huse and E. C. Holland, "Targeting brain cancer: advances in the molecular pathology of malignant glioma and medulloblastoma," Nature Reviews Cancer, vol. 10, no. 5, pp. 319-331, 2010.

[13] Z. Piotrowska and L. V. Sequist, "Epidermal growth factor receptor-mutant lung cancer: New drugs, new resistance mechanisms, and future treatment options," Cancer Journal, vol. 21, no. 5, pp. 371-377, 2015.

[14] N. Chang, S. H. Ahn, D.-S. Kong, H. W. Lee, and D.-H. Nam, "The role of STAT3 in glioblastoma progression through dual influences on tumor cells and the immune microenvironment," Molecular and Cellular Endocrinology, vol. 451, pp. 53-65, 2017.

[15] Z. G. Ouédraogo, J. Biau, J.-L. Kemeny, L. Morel, P. Verrelle, and E. Chautard, "Role of STAT3 in genesis and progression of human malignant gliomas," Molecular Neurobiology, vol. 54, no. 8, pp. 5780-5797, 2017.

[16] A. Mostofa, S. R. Punganuru, H. R. Madala, M. Al-Obaide, and K. S. Srivenugopal, "The process and regulatory components of inflammation in brain oncogenesis," Biomolecules, vol. 7, no. 2, p. 34, 2017.

[17] J. J. Miller and P. Y. Wen, "Emerging targeted therapies for glioma," Expert Opinion on Emerging Drugs, vol. 21, no. 4, pp. 441-452, 2016.

[18] C. L. Arteaga, "Overview of epidermal growth factor receptor biology and its role as a therapeutic target in human neoplasia," Seminars in Oncology, vol. 29, no. 5, pp. 3-9, 2002.

[19] D. A. Reardon, P. Y. Wen, and I. K. Mellinghoff, "Targeted molecular therapies against epidermal growth factor receptor: past experiences and challenges," Neuro-Oncology, vol. 16, pp. viii7-viiil3, 2014.

[20] Z. Duzgun, Z. Eroglu, and C. Biray Avci, "Role of mTOR in glioblastoma," Gene, vol. 575, no. 2, pp. 187-190, 2016.
[21] A. Sami and M. Karsy, "Targeting the PI3K/AKT/mTOR signaling pathway in glioblastoma: novel therapeutic agents and advances in understanding," Tumor Biology, vol. 34, no. 4, pp. 1991-2002, 2013.

[22] D. J. Ma, E. Galanis, S. K. Anderson et al., "A phase II trial of everolimus, temozolomide, and radiotherapy in patients with newly diagnosed glioblastoma: NCCTG N057K," NeuroOncology, vol. 17, no. 9, pp. 1261-1269, 2015.

[23] S. K. Carlsson, S. P. Brothers, and C. Wahlestedt, "Emerging treatment strategies for glioblastoma multiforme," EMBO Molecular Medicine, vol. 6, no. 11, pp. 1359-1370, 2014.

[24] A. Merlo, "Genes and pathways driving glioblastomas in humans and murine disease models," Neurosurgical Review, vol. 26, no. 3, pp. 145-158, 2003.

[25] B. Sarcar, S. Kahali, A. H. Prabhu et al., "Targeting radiationinduced $\mathrm{G} 2$ checkpoint activation with the wee-1 inhibitor MK1775 in glioblastoma cell lines," Molecular Cancer Therapeutics, vol. 10, no. 12, pp. 2405-2414, 2011.

[26] L. R. Werner, S. Huang, D. M. Francis et al., "Small molecule inhibition of MDM2-p53 interaction augments radiation response in human tumors," Molecular Cancer Therapeutics, vol. 14, no. 9, pp. 1994-2003, 2015.

[27] T. Hundsberger, D. A. Reardon, and P. Y. Wen, "Angiogenesis inhibitors in tackling recurrent glioblastoma," Expert Review of Anticancer Therapy, vol. 17, no. 6, pp. 507-515, 2017.

[28] C. Lu-Emerson, D. G. Duda, K. E. Emblem et al., "Lessons from anti-vascular endothelial growth factor and anti-vascular endothelial growth factor receptor trials in patients with Glioblastoma," Journal of Clinical Oncology, vol. 33, no. 10, pp. 1197-1213, 2015.

[29] J. Kloepper, L. Riedemann, Z. Amoozgar et al., "Ang-2/VEGF bispecific antibody reprograms macrophages and resident microglia to anti-tumor phenotype and prolongs glioblastoma survival," in Proceedings of the National Academy of Sciences, vol. 113, pp. 4476-4481, USA, 2016.

[30] K. Ludwig and H. I. Kornblum, "Molecular markers in glioma," Journal of Neuro-Oncology, vol. 134, no. 3, pp. 505-512, 2017.

[31] R. Velho-Pereira, A. Kumar, B. N. Pandey, A. G. Jagtap, and K. P. Mishra, "Radiosensitization in human breast carcinoma cells by thymoquinone: role of cell cycle and apoptosis," Cell Biology International, vol. 35, no. 10, pp. 1025-1029, 2011.

[32] L. Dang, D. W. White, S. Gross et al., "Cancer-associated IDH1 mutations produce 2-hydroxyglutarate," Nature, vol. 462, no. 7274, pp. 739-744, 2009.

[33] L. E. Jalbert, A. Elkhaled, J. J. Phillips et al., "Metabolic profiling of IDH mutation and malignant progression in infiltrating glioma," Scientific Reports, vol. 7, Article ID 44792, 2017.

[34] L. Annovazzi, M. Mellai, and D. Schiffer, "Chemotherapeutic drugs: DNA damage and repair in glioblastoma," Cancers, vol. 9, no. 6, p. 57, 2017.

[35] T. Seymour, A. Nowak, and F. Kakulas, "Targeting aggressive cancer stem cells in glioblastoma," Frontiers in Oncology, vol. 5, p. 159, 2015.

[36] L. Wei, Y.-K. Su, C.-M. Lin et al., "Preclinical investigation of ibrutinib, a Bruton's kinase tyrosine (Btk) inhibitor, in suppressing glioma tumorigenesis and stem cell phenotypes," Oncotarget , vol. 7, no. 43, pp. 69961-69975, 2016.

[37] R. Xu, F. Shimizu, K. Hovinga et al., "Molecular and clinical effects of notch inhibition in glioma patients: A phase 0/I trial," Clinical Cancer Research, vol. 22, no. 19, pp. 4786-4796, 2016. 
[38] C. Alifieris and D. T. Trafalis, "Glioblastoma multiforme: pathogenesis and treatment," Pharmacology \& Therapeutics, vol. 152, pp. 63-82, 2015.

[39] M. J. Salomi, S. C. Nair, and K. R. Panikkar, "Inhibitory effects of Nigella sativa and saffron (Crocus sativus) on chemical carcinogenesis in mice," Nutrition and Cancer, vol. 16, no. 1, pp. 67-72, 1991.

[40] F. I. Al-Jenoobi, A. A. Al-Thukair, F. A. Abbas et al., "Effect of black seed on dextromethorphan $\mathrm{O}$ - and $\mathrm{N}$-demethylation in human liver microsomes and healthy human subjects," Drug Metabolism Letters, vol. 4, no. 1, pp. 51-55, 2010.

[41] F. R. Dehkordi and A. F. Kamkhah, "Antihypertensive effect of Nigella sativa seed extract in patients with mild hypertension," Fundamental \& Clinical Pharmacology, vol. 22, no. 4, pp. 447$452,2008$.

[42] M. S. B. Sayeed, M. Asaduzzaman, H. Morshed, M. M. Hossain, M. F. Kadir, and M. R. Rahman, "The effect of Nigella sativa Linn. seed on memory, attention and cognition in healthy human volunteers," Journal of Ethnopharmacology, vol. 148, no. 3, pp. 780-786, 2013.

[43] M. S. Bin Sayeed, T. Shams, S. F. Hossain et al., "Nigella sativa L. seeds modulate mood, anxiety and cognition in healthy adolescent males," Journal of Ethnopharmacology, vol. 152, no. 1, pp. 156-162, 2014.

[44] F. J. Marozzi Jr., A. B. Kocialski, and M. H. Malone, "Studies on the antihistaminic effects of thymoquinone, thymohydroquinone and quercetin.", Arzneimittel-Forschung/Drug Research, vol. 20, no. 10, pp. 1574-1577, 1970.

[45] M. El-Dakhakhny, "Studies on the chemical composition of Egyptian Nigella sativa L. Seed II1) The essential oil," Planta Medica, vol. 11, no. 04, pp. 465-470, 1963.

[46] H. U. Gali-Muhtasib, W. G. Abou Kheir, L. A. Kheir, N. Darwiche, and P. A. Crooks, "Molecular pathway for thymoquinone-induced cell-cycle arrest and apoptosis in neoplastic keratinocytes," Anti-Cancer Drugs, vol. 15, no. 4, pp. 389-399, 2004.

[47] L. Peng, A. Liu, Y. Shen et al., "Antitumor and anti-angiogenesis effects of thymoquinone on osteosarcoma through the NFkappaB pathway," Oncology Reports, vol. 29, pp. 571-578, 2013.

[48] M. A. Khan, M. Tania, C. Wei et al., "Thymoquinone inhibits cancer metastasis by downregulating TWIST1 expression to reduce epithelial to mesenchymal transition," Oncotarget, vol. 6, no. 23, pp. 19580-19591, 2015.

[49] J. Kundu, K.-S. Chun, O. I. Aruoma, and J. K. Kundu, "Mechanistic perspectives on cancer chemoprevention/chemotherapeutic effects of thymoquinone," Mutation Research - Fundamental and Molecular Mechanisms of Mutagenesis, vol. 768, no. C, pp. 22-34, 2014.

[50] L. Zhang, Y. Bai, and Y. Yang, "Thymoquinone chemosensitizes colon cancer cells through inhibition of NF- $\kappa \mathrm{B}$," Oncology Letters, vol. 12, no. 4, pp. 2840-2845, 2016.

[51] D. Hanahan and R. A. Weinberg, "Hallmarks of cancer: the next generation,” Cell, vol. 144, no. 5, pp. 646-674, 2011.

[52] A. Omuro and L. M. DeAngelis, "Glioblastoma and other malignant gliomas: A clinical review," Journal of the American Medical Association, vol. 310, no. 17, pp. 1842-1850, 2013.

[53] K. Aldape, G. Zadeh, S. Mansouri, G. Reifenberger, and A. von Deimling, "Glioblastoma: pathology, molecular mechanisms and markers," Acta Neuropathologica, vol. 129, no. 6, pp. 829848, 2015.
[54] H. P. Ellis, M. Greenslade, B. Powell, I. Spiteri, A. Sottoriva, and K. M. Kurian, "Current challenges in glioblastoma: Intratumour heterogeneity, residual disease, and models to predict disease recurrence," Frontiers in Oncology, vol. 5, article no. 251, 2015.

[55] O. O. Kanu, A. Mehta, C. Di et al., "Glioblastoma multiforme: a review of therapeutic targets," Expert Opinion on Therapeutic Targets, vol. 13, no. 6, pp. 701-718, 2009.

[56] J. H. Kang and C. Adamson, "Novel chemotherapeutics and other therapies for treating high-grade glioma," Expert Opinion on Investigational Drugs, vol. 24, no. 10, pp. 1361-1379, 2015.

[57] A. F. Majdalawieh, M. W. Fayyad, and G. K. Nasrallah, "Anticancer properties and mechanisms of action of thymoquinone, the major active ingredient of Nigella sativa," Critical Reviews in Food Science and Nutrition, vol. 57, no. 18, pp. 3911-3928, 2016.

[58] M. Asaduzzaman Khan, M. Tania, S. Fu, and J. Fu, “Thymoquinone, as an anticancer molecule: from basic research to clinical investigation," Oncotarget, vol. 2017, pp. 51907-51919, 2017.

[59] A. H. Rahmani, M. A. Alzohairy, M. A. Khan, and S. M. Aly, "Therapeutic implications of black seed and its constituent thymoquinone," Evidence-Based Complementary and Alternative Medicine, vol. 2014, Article ID 724658, 13 pages, 2014.

[60] A. Mostofa, M. K. Hossain, D. Basak, and M. S. Bin Sayeed, "Thymoquinone as a Potential Adjuvant Therapy for Cancer Treatment: Evidence from Preclinical Studies," Frontiers in Pharmacology, vol. 8, 2017.

[61] M. Nakada, D. Kita, T. Watanabe et al., "Aberrant signaling pathways in Glioma," Cancers, vol. 3, no. 3, pp. 3242-3278, 2011.

[62] B. B. Friday and A. A. Adjei, "Advances in targeting the Ras/Raf/MEK/Erk mitogen-activated protein kinase cascade with MEK inhibitors for cancer therapy," Clinical Cancer Research, vol. 14, no. 2, pp. 342-346, 2008.

[63] A. B. Heimberger, R. Hlatky, D. Suki et al., "Prognostic effect of epidermal growth factor receptor and EGFRvIII in glioblastoma multiforme patients," Clinical Cancer Research, vol. 11, no. 4, pp. 1462-1466, 2005.

[64] T. P. Fleming, A. Saxena, W. C. Clark et al., "Amplification and/or overexpression of platelet-derived growth factor receptors and epidermal growth factor receptor in human glial tumors," Cancer Research, vol. 52, no. 16, pp. 4550-4553, 1992.

[65] M. S. Ahluwalia, J. D. Groot, W. M. Liu, and C. L. Gladson, "Targeting SRC in glioblastoma tumors and brain metastases: Rationale and preclinical studies," Cancer Letters, vol. 298, no. 2, pp. 139-149, 2010.

[66] M. Bredel and I. F. Pollack, "The p21-Ras signal transduction pathway and growth regulation in human high-grade gliomas," Brain Research Reviews, vol. 29, no. 2-3, pp. 232-249, 1999.

[67] D. Smith, T. Shimamura, S. Barbera, and B. E. Bejcek, "NF- $\kappa$ B controls growth of glioblastomas/astrocytomas," Molecular and Cellular Biochemistry, vol. 307, no. 1-2, pp. 141-147, 2007.

[68] E. A. Beierle, N. A. Massoll, J. Hartwich et al., "Focal adhesion kinase expression in human neuroblastoma: immunohistochemical and real-time PCR analyses," Clinical Cancer Research, vol. 14, no. 11, pp. 3299-3305, 2008.

[69] J. Zhao and J. Guan, "Signal transduction by focal adhesion kinase in cancer," Cancer and Metastasis Reviews, vol. 28, no. 1-2, pp. 35-49, 2009.

[70] D. D. Schlaepfer, S. K. Mitra, and D. Ilic, "Control of motile and invasive cell phenotypes by focal adhesion kinase," Biochimica et Biophysica Acta, vol. 1692, no. 2-3, pp. 77-102, 2004. 
[71] M. Natarajan, T. P. Hecker, and C. L. Gladson, "FAK signaling in anaplastic astrocytoma and glioblastoma tumors," Cancer Journal, vol. 9, no. 2, pp. 126-133, 2003.

[72] E.-S. A. Arafa, Q. Zhu, Z. I. Shah et al., “Thymoquinone up-regulates PTEN expression and induces apoptosis in doxorubicinresistant human breast cancer cells," Mutation Research - Fundamental and Molecular Mechanisms of Mutagenesis, vol. 706, no. 1-2, pp. 28-35, 2011.

[73] G.-G. Mu, L.-L. Zhang, H.-Y. Li, Y. Liao, and H.-G. Yu, "Thymoquinone pretreatment overcomes the insensitivity and potentiates the antitumor effect of gemcitabine through abrogation of notchl, PI3K/Akt/mTOR regulated signaling pathways in pancreatic cancer," Digestive Diseases and Sciences, vol. 60, no. 4, pp. 1067-1080, 2015.

[74] S. Rajput, B. N. Kumar, K. K. Dey, I. Pal, A. Parekh, and M. Mandal, "Molecular targeting of Akt by thymoquinone promotes $G(1)$ arrest through translation inhibition of cyclin D1 and induces apoptosis in breast cancer cells," Life Sciences, vol. 93, pp. 783-790, 2013.

[75] K. M. Sutton, A. L. Greenshields, and D. W. Hoskin, “Thymoquinone, a bioactive component of black caraway seeds, causes G1 phase cell cycle arrest and apoptosis in triple-negative breast cancer cells with mutant p53," Nutrition and Cancer, vol. 66, no. 3, pp. 408-418, 2014.

[76] D. Xu, Y. Ma, B. Zhao et al., "Thymoquinone induces G2/M arrest, inactivates PI3K/Akt and nuclear factor $-\kappa \mathrm{B}$ pathways in human cholangiocarcinomas both in vitro and in vivo," Oncology Reports, vol. 31, no. 5, pp. 2063-2070, 2014.

[77] B. Iskender, K. Izgi, E. Hizar et al., "Inhibition of epithelialmesenchymal transition in bladder cancer cells via modulation of mTOR signalling," Tumor Biology, vol. 37, no. 6, pp. 82818291, 2016.

[78] B. Iskender, K. Izgi, and H. Canatan, "Novel anti-cancer agent myrtucommulone-A and thymoquinone abrogate epithelialmesenchymal transition in cancer cells mainly through the inhibition of PI3K/AKT signalling axis," Molecular and Cellular Biochemistry, vol. 416, no. 1-2, pp. 71-84, 2016.

[79] C. El-Baba, V. Mahadevan, F. B. Fahlbusch et al., "Thymoquinone-induced conformational changes of PAK1 interrupt prosurvival MEK-ERK signaling in colorectal cancer," Molecular Cancer, vol. 13, no. 1, article no. 201, 2014.

[80] H. Aoki, T. Yokoyama, K. Fujiwara et al., "Phosphorylated Pak1 level in the cytoplasm correlates with shorter survival time in patients with glioblastoma," Clinical Cancer Research, vol. 13, no. 22, pp. 6603-6609, 2007.

[81] P. Arumugam, R. Subramanian, J. V. Priyadharsini, and J. Gopalswamy, "Thymoquinone inhibits the migration of mouse neuroblastoma (Neuro-2a) cells by down-regulating MMP-2 and MMP-9," Chinese Journal of Natural Medicines, vol. 14, no. 12, pp. 904-912, 2016.

[82] K. Kolli-Bouhafs, A. Boukhari, A. Abusnina et al., "Thymoquinone reduces migration and invasion of human glioblastoma cells associated with FAK, MMP-2 and MMP-9 downregulation," Investigational New Drugs, vol. 30, no. 6, pp. 21212131, 2012.

[83] A. Shoieb, M. Elgayyar, P. Dudrick, J. Bell, and P. Tithof, "In vitro inhibition of growth and induction of apoptosis in cancer cell lines by thymoquinone," International Journal of Oncology, 2003.

[84] S. Darakhshan, A. Bidmeshki Pour, A. Hosseinzadeh Colagar, and S. Sisakhtnezhad, "Thymoquinone and its therapeutic potentials," Pharmacological Research, vol. 95-96, pp. 138-158, 2015.

[85] A. O. Kaseb, K. Chinnakannu, D. Chen et al., "Androgen receptor- and E2F-1-targeted thymoquinone therapy for hormone-refractory prostate cancer," Cancer Research, vol. 67, no. 16, pp. 7782-7788, 2007.

[86] F. Li, P. Rajendran, and G. Sethi, “Thymoquinone inhibits proliferation, induces apoptosis and chemosensitizes human multiple myeloma cells through suppression of signal transducer and activator of transcription 3 activation pathway," British Journal of Pharmacology, vol. 161, no. 3, pp. 541-554, 2010.

[87] M. Alhosin, A. Ibrahim, A. Boukhari et al., "Anti-neoplastic agent thymoquinone induces degradation of $\alpha$ and $\beta$ tubulin proteins in human cancer cells without affecting their level in normal human fibroblasts," Investigational New Drugs, vol. 30, no. 5, pp. 1813-1819, 2012.

[88] A. Paramasivam, S. Sambantham, J. Shabnam et al., "Anticancer effects of thymoquinone in mouse neuroblastoma (Neuro-2a) cells through caspase-3 activation with downregulation of XIAP," Toxicology Letters, vol. 213, no. 2, pp. 151159, 2012.

[89] H. Zubair, H. Y. Khan, A. Sohail et al., "Redox cycling of endogenous copper by thymoquinone leads to ROS-mediated DNA breakage and consequent cell death: Putative anticancer mechanism of antioxidants," Cell Death \& Disease, vol. 4, no. 6, article no. e660, 2013.

[90] A. R. Hussain, M. Ahmed, S. Ahmed et al., "Thymoquinone suppresses growth and induces apoptosis via generation of reactive oxygen species in primary effusion lymphoma," Free Radical Biology \& Medicine, vol. 50, no. 8, pp. 978-987, 2011.

[91] T. Fröhlich, B. Ndreshkjana, J. K. Muenzner et al., "Synthesis of Novel Hybrids of Thymoquinone and Artemisinin with High Activity and Selectivity Against Colon Cancer," ChemMedChem, vol. 12, no. 3, pp. 226-234, 2017.

[92] G. Sethi, K. S. Ahn, and B. B. Aggarwal, "Targeting nuclear factor- $\kappa \mathrm{B}$ activation pathway by thymoquinone: role in suppression of antiapoptotic gene products and enhancement of apoptosis," Molecular Cancer Research, vol. 6, no. 6, pp. 10591070, 2008.

[93] A. E. Ashour, A. F. Ahmed, A. Kumar et al., “Thymoquinone inhibits growth of human medulloblastoma cells by inducing oxidative stress and caspase-dependent apoptosis while suppressing NF- $\kappa \mathrm{B}$ signaling and IL-8 expression," Molecular and Cellular Biochemistry, vol. 416, no. 1-2, pp. 141-155, 2016.

[94] R. L. Gurung, S. N. Lim, A. K. Khaw et al., "Thymoquinone induces telomere shortening, DNA damage and apoptosis in human glioblastoma cells," PLoS ONE, vol. 5, no. 8, Article ID e12124, 2010.

[95] A. Kurimasa, S. Kumano, N. V. Boubnov et al., "Requirement for the kinase activity of human DNA-dependent protein kinase catalytic subunit in DNA strand break rejoining," Molecular and Cellular Biology, vol. 19, no. 5, pp. 3877-3884, 1999.

[96] G. G. Chen, F. L. F. Sin, B. C. S. Leung, H. K. Ng, and W. S. Poon, "Glioblastoma cells deficient in DNA-dependent protein kinase are resistant to cell death," Journal of Cellular Physiology, vol. 203, no. 1, pp. 127-132, 2005.

[97] A. A. Salem, I. A. El Haty, I. M. Abdou, and Y. Mu, "Interaction of human telomeric G-quadruplex DNA with thymoquinone: A possible mechanism for thymoquinone anticancer effect," Biochimica et Biophysica Acta (BBA) - General Subjects, vol. 1850, no. 2, pp. 329-342, 2015. 
[98] M. Safari and A. Khoshnevisan, "Cancer stem cells and chemoresistance in glioblastoma multiform: A review article," Journal of Stem Cells, vol. 10, no. 4, pp. 271-285, 2015.

[99] Y. P. Ramirez, J. L. Weatherbee, R. T. Wheelhouse, and A. H. Ross, "Glioblastoma multiforme therapy and mechanisms of resistance," Pharmaceuticals, vol. 6, no. 12, pp. 1475-1506, 2013.

[100] S. Bao, Q. Wu, R. E. McLendon et al., "Glioma stem cells promote radioresistance by preferential activation of the DNA damage response," Nature, vol. 444, no. 7120, pp. 756-760, 2006.

[101] L. Cheng, Q. Wu, Z. Huang et al., "L1CAM regulates DNA damage checkpoint response of glioblastoma stem cells through NBS1," EMBO Journal, vol. 30, no. 5, pp. 800-813, 2011.

[102] G. Liu, "Analysis of gene expression and chemoresistance of CD133+ cancer stem cells in glioblastoma," Molecular Cancer, vol. 5, p. 67, 2006.

[103] H. Gali-Muhtasib, D. Kuester, C. Mawrin et al., “Thymoquinone triggers inactivation of the stress response pathway sensor CHEK1 and contributes to apoptosis in colorectal cancer cells," Cancer Research, vol. 68, pp. 5609-5618, 2008.

[104] D. Capper, T. Gaiser, C. Hartmann et al., "Stem-cell-like glioma cells are resistant to TRAIL/Apo2L and exhibit down-regulation of caspase- 8 by promoter methylation," Acta Neuropathologica, vol. 117, no. 4, pp. 445-456, 2009.

[105] C. Zang, M. Wächter, H. Liu et al., "Ligands for PPAR $\gamma$ and RAR cause induction of growth inhibition and apoptosis in human glioblastomas," Journal of Neuro-Oncology, vol. 65, no. 2, pp. 107-118, 2003.

[106] L. Ricci-Vitiani, F. Pedini, C. Mollinari et al., "Absence of caspase 8 and high expression of PED protect primitive neural cells from cell death," The Journal of Experimental Medicine, vol. 200, no. 10, pp. 1257-1266, 2004.

[107] C. P. Haar, P. Hebbar, G. C. Wallace IV et al., "Drug resistance in glioblastoma: A mini review," Neurochemical Research, vol. 37, no. 6, pp. 1192-1200, 2012.

[108] X. Lei, X. Lv, M. Liu et al., "Thymoquinone inhibits growth and augments 5-fluorouracil-induced apoptosis in gastric cancer cells both in vitro and in vivo," Biochemical and Biophysical Research Communications, vol. 417, no. 2, pp. 864-868, 2012.

[109] Y. Kondo, S. Kondo, Y. Tanaka, T. Haqqi, B. P. Barna, and J. K. Cowell, "Inhibition of telomerase increases the susceptibility of human malignant glioblastoma cells to cisplatin-induced apoptosis," Oncogene, vol. 16, no. 17, pp. 2243-2248, 1998.

[110] P. Vaupel, D. K. Kelleher, and M. Höckel, “Oxygenation status of malignant tumors: pathogenesis of hypoxia and significance for tumor therapy," Seminars in Oncology, vol. 28, no. 2, supplement 8, pp. 29-35, 2001.

[111] L. Oliver, C. Olivier, F. Marhuenda, M. Campone, and F. Vallette, "Hypoxia and the Malignant Glioma Microenvironment: Regulation and Implications for Therapy," Current Molecular Pharmacologye, vol. 2, no. 3, pp. 263-284, 2009.

[112] K. M. Comerford, T. J. Wallace, J. Karhausen, N. A. Louis, M. C. Montalto, and S. P. Colgan, "Hypoxia-inducible factor1-dependent regulation of the multidrug resistance (MDR1) gene," Cancer Research, vol. 62, no. 12, pp. 3387-3394, 2002.

[113] M. Tafani, L. Sansone, F. Limana et al., "The interplay of reactive oxygen species, hypoxia, inflammation, and sirtuins in cancer initiation and progression," Oxidative Medicine and Cellular Longevity, vol. 2016, Article ID 3907147, 2016.

[114] M. A. Mansour, M. N. Nagi, A. S. El-Khatib, and A. M. AlBekairi, "Effects of thymoquinone on antioxidant enzyme activities, lipid peroxidation and dt-diaphorase in different tissues of mice: A possible mechanism of action," Cell Biochemistry \& Function, vol. 20, no. 2, pp. 143-151, 2002.

[115] I. O. Racoma, W. H. Meisen, Q.-E. Wang, B. Kaur, and A. A. Wani, "Thymoquinone inhibits autophagy and induces cathepsin-mediated, caspase-independent cell death in glioblastoma cells," PLoS ONE, vol. 8, no. 9, Article ID e72882, 2013.

[116] X. Fan, W. Matsui, L. Khaki et al., "Notch pathway inhibition depletes stem-like cells and blocks engraftment in embryonal brain tumors," Cancer Research, vol. 66, no. 15, pp. 7445-7452, 2006.

[117] J. Wang, T. P. Wakeman, J. D. Lathia et al., "Notch promotes radioresistance of glioma stem cells," Stem Cells, vol. 28, no. 1, pp. 17-28, 2010.

[118] S. Banerjee, A. O. Kaseb, Z. Wang et al., "Antitumor activity of gemcitabine and oxaliplatin is augmented by thymoquinone in pancreatic cancer," Cancer Research, vol. 69, pp. 5575-5583, 2009.

[119] J. Sigmond, R. J. Honeywell, T. J. Postma et al., "Gemcitabine uptake in glioblastoma multiforme: Potential as a radiosensitizer," Annals of Oncology, vol. 20, no. 1, pp. 182-187, 2009.

[120] P. Zhao, Y.-Z. Zhang, and M.-Z. Sun, "Regulatory effect of small interfering RNA targeting multidrug resistant protein 1 on chemosensitivity of human multiforme glioblastoma cell line BT325," Aizheng=Chinese journal of cancer, vol. 24, no. 12, pp. 1436-1441, 2005.

[121] T. Tsuruo, M. Naito, A. Tomida et al., "Molecular targeting therapy of cancer: drug resistance, apoptosis and survival signal," Cancer Science, vol. 94, no. 1, pp. 15-21, 2003.

[122] D. Wang, J. Qiao, X. Zhao, T. Chen, and D. Guan, “Thymoquinone Inhibits IL- $1 \beta$-Induced Inflammation in Human Osteoarthritis Chondrocytes by Suppressing NF- $\kappa$ B and MAPKs Signaling Pathway," Inflammation, vol. 38, no. 6, pp. 2235-2241, 2015.

[123] R. Stupp, W. P. Mason, and M. J. van den Bent, "Radiotherapy plus concomitant and adjuvant temozolomide for glioblastoma," Oncology Times, vol. 27, no. 9, pp. 15-16, 2005.

[124] M. Pazhouhi, R. Sariri, A. Rabzia, and M. Khazaei, “Thymoquinone synergistically potentiates temozolomide cytotoxicity through the inhibition of autophagy in U87MG cell line," Iranian Journal of Basic Medical Sciences, vol. 19, no. 8, pp. 890898, 2016.

[125] G. A. Garden, "Epigenetics and the Modulation of Neuroinflammation," Neurotherapeutics, vol. 10, no. 4, pp. 782-788, 2013.

[126] C. L. Mayer, B. R. Huber, and E. Peskind, "Traumatic brain injury, neuroinflammation, and post-traumatic headaches," Headache: The Journal of Head and Face Pain, vol. 53, no. 9, pp. 1523-1530, 2013.

[127] W. J. Streit, R. E. Mrak, and W. S. T. Griffin, "Microglia and neuroinflammation: a pathological perspective," Journal of Neuroinflammation, vol. 1, article 14, 2004.

[128] S. Razavi, K. E. Lee, B. E. Jin, P. S. Aujla, S. Gholamin, and G. $\mathrm{Li}$, "Immune Evasion Strategies of Glioblastoma," Frontiers in Surgery, vol. 3, 2016.

[129] N. Kamran et al., "Recent advances and future of immunotherapy for glioblastoma," Expert Opin Biol Ther, vol. 16, no. 10, pp. 1245-1264, 2016.

[130] D. I. Gabrilovich and S. Nagaraj, "Myeloid-derived suppressor cells as regulators of the immune system," Nature Reviews Immunology, vol. 9, no. 3, pp. 162-174, 2009. 
[131] O. Bloch, C. A. Crane, R. Kaur, M. Safaee, M. J. Rutkowski, and A. T. Parsa, "Gliomas promote immunosuppression through induction of B7-H1 expression in tumor-associated macrophages," Clinical Cancer Research, vol. 19, no. 12, pp. 3165-3175, 2013.

[132] J. E. Kim and M. Lim, "The role of checkpoints in the treatment of GBM," Journal of Neuro-Oncology, vol. 123, no. 3, pp. 413-423, 2015.

[133] M. Hatano, J. Eguchi, T. Tatsumi et al., "EphA2 as a gliomaassociated antigen: a novel target for glioma vaccines," Neoplasia, vol. 7, no. 8, pp. 717-722, 2005.

[134] R. M. Prins, X. Wang, H. Soto et al., "Comparison of gliomaassociated antigen peptide-loaded versus autologous tumor lysate-loaded dendritic cell vaccination in malignant glioma patients," Journal of Immunotherapy, vol. 36, no. 2, pp. 152-157, 2013.

[135] D. M. Haynik, A. A. Roma, and R. A. Prayson, "HER-2/neu expression in glioblastoma multiforme," Applied Immunohistochemistry \& Molecular Morphology, vol. 15, no. 1, pp. 56-58, 2007.

[136] J. H. Sampson et al., "mmunologic escape after prolonged progression-free survival with epidermal growth factor receptor variant III peptide vaccination in patients with newly diagnosed glioblastoma," J Clin Oncol, vol. 31, pp. 4722-4729, 28.

[137] M. P. Torres, M. P. Ponnusamy, S. Chakraborty et al., "Effects of thymoquinone in the expression of mucin 4 in pancreatic cancer cells: implications for the development of novel cancer therapies," Molecular Cancer Therapeutics, vol. 9, no. 5, pp. 14191431, 2010.

[138] K. Palucka and J. Banchereau, "Cancer immunotherapy via dendritic cells," Nature Reviews Cancer, vol. 12, no. 4, pp. 265277, 2012.

[139] D. A. Mitchell, K. A. Batich, M. D. Gunn et al., "Tetanus toxoid and CCL3 improve dendritic cell vaccines in mice and glioblastoma patients," Nature, vol. 519, no. 7543, pp. 366-369, 2015.

[140] A.-A. Calinescu, N. Kamran, G. Baker, Y. Mineharu, P. R. Lowenstein, and M. G. Castro, "Overview of current immunotherapeutic strategies for glioma," Immunotherapy, vol. 7, no. 10, pp. 1073-1104, 2015.

[141] D. Kirn, T. Hermiston, and F. McCormick, "ONYX-015: Clinical data are encouraging," Nature Medicine, vol. 4, no. 12, pp. 13411342, 1998.

[142] G. Liu, H. Ying, G. Zeng, C. J. Wheeler, K. L. Black, and J. S. Yu, "HER-2, gp100, and MAGE-1 are expressed in human glioblastoma and recognized by cytotoxic T cells," Cancer Research, vol. 64, no. 14, pp. 4980-4986, 2004.

[143] N. T. Xuan, E. Shumilina, S. M. Qadri, F. Götz, and F. Lang, "Effect of thymoquinone on mouse dendritic cells," Cellular Physiology and Biochemistry, vol. 25, no. 2-3, pp. 307-314, 2010.

[144] W. Yang, M. Bhandaru, V. Pasham et al., "Effect of thymoquinone on cytosolic $\mathrm{pH}$ and $\mathrm{Na} / \mathrm{H}+$ exchanger activity in mouse dendritic cells," Cellular Physiology and Biochemistry, vol. 29, no. 1-2, pp. 21-30, 2012.

[145] Z. Su, M.-F. Tam, D. Jankovic, and M. M. Stevenson, "Vaccination with novel immunostimulatory adjuvants against bloodstage malaria in mice," Infection and Immunity, vol. 71, no. 9, pp. 5178-5187, 2003.

[146] L. L. R. Hartman, J. R. Crawford, M. T. Makale et al., "Pediatric phase II trials of poly-ICLC in the management of newly diagnosed and recurrent brain tumors," Journal of Pediatric Hematology/Oncology, vol. 36, no. 6, pp. 451-457, 2014.
[147] M. R. Rosenfeld, M. C. Chamberlain, S. A. Grossman et al., "A multi-institution phase II study of poly-ICLC and radiotherapy with concurrent and adjuvant temozolomide in adults with newly diagnosed glioblastoma," Neuro-Oncology, vol. 12, no. 10, pp. 1071-1077, 2010.

[148] S. R. Amith, P. Jayanth, T. Finlay et al., "Detection of Neul Sialidase Activity in Regulating TOLL-like Receptor Activation," Journal of Visualized Experiments, no. 43, 2010.

[149] T. M. Finlay, P. Jayanth, S. R. Amith et al., "Thymoquinone from nutraceutical black cumin oil activates Neu4 sialidase in live macrophage, dendritic, and normal and type i sialidosis human fibroblast cells via GPCR G $\alpha$ i proteins and matrix metalloproteinase-9," Glycoconjugate Journal, vol. 27, no. 3, pp. 329-348, 2010.

[150] Y. Shan, X. He, W. Song, D. Han, J. Niu, and J. Wang, "Role of IL-6 in the invasiveness and prognosis of glioma," International Journal of Clinical and Experimental Medicine, vol. 8, no. 6, pp. 9114-9120, 2015.

[151] E. G. Van Meir, "Cytokines and tumors of the central nervous system," Glia, vol. 15, no. 3, pp. 264-288, 1995.

[152] D. Lobo-Silva, G. M. Carriche, A. G. Castro, S. Roque, and M. Saraiva, "Balancing the immune response in the brain: IL-10 and its regulation," Journal of Neuroinflammation, vol. 13, no. 1, article no. 297, 2016.

[153] K. Strle, "Interleukin-10 in the brain," Crit Rev Immunol, vol. 21, no. 5, pp. 427-49, 2001.

[154] J. Han, C. A. Alvarez-Breckenridge, Q.-E. Wang, and J. Yu, "TGF-beta signaling and its targeting for glioma treatment," American Journal of Cancer Research, vol. 5, no. 3, pp. 945-955, 2015.

[155] I. Tritschler, D. Gramatzki, D. Capper et al., "Modulation of TGF- $\beta$ activity by latent TGF- $\beta$-binding protein 1 in human malignant glioma cells," International Journal of Cancer, vol. 125, no. 3, pp. 530-540, 2009.

[156] Y. Lin, G. Zhang, J. Zhang et al., "A panel of four cytokines predicts the prognosis of patients with malignant gliomas," Journal of Neuro-Oncology, vol. 114, no. 2, pp. 199-208, 2013.

[157] S. Umar, O. Hedaya, A. K. Singh, and S. Ahmed, "Thymoquinone inhibits TNF- $\alpha$-induced inflammation and cell adhesion in rheumatoid arthritis synovial fibroblasts by ASK1 regulation," Toxicology and Applied Pharmacology, vol. 287, no. 3, pp. 299-305, 2015.

[158] E. Taka, E. A. Mazzio, C. B. Goodman et al., "Anti-inflammatory effects of thymoquinone in activated BV-2 microglial cells," Journal of Neuroimmunology, vol. 286, pp. 5-12, 2015.

[159] M. Khazaei and M. Pazhouhi, "Temozolomide-Mediated Apoptotic Death Is Improved by Thymoquinone in U87MG Cell Line," Cancer Investigation, vol. 35, no. 4, pp. 225-236, 2017.

[160] E. I. Buchbinder and A. Desai, "CTLA-4 and PD-1 pathways: similarities, differences, and implications of their inhibition," American Journal of Clinical Oncology, vol. 39, no. 1, pp. 98-106, 2015.

[161] A. Schuessler, C. Smith, L. Beagley et al., "Autologous T-cell therapy for cytomegalovirus as a consolidative treatment for recurrent glioblastoma," Cancer Research, vol. 74, no. 13, pp. 3466-3476, 2014.

[162] M. A. Curran, W. Montalvo, H. Yagita, and J. P. Allison, "PD1 and CTLA-4 combination blockade expands infiltrating T cells and reduces regulatory $\mathrm{T}$ and myeloid cells within B16 melanoma tumors," Proceedings of the National Acadamy of Sciences of the United States of America, vol. 107, no. 9, pp. 42754280, 2010. 
[163] S. G. M. Piccirillo, B. A. Reynolds, N. Zanetti et al., "Bone morphogenetic proteins inhibit the tumorigenic potential of human brain tumour-initiating cells," Nature, vol. 444, no. 7120, pp. 761-765, 2006.

[164] J. M. Garner, M. Fan, C. H. Yang et al., "Constitutive activation of signal transducer and activator of transcription 3 (STAT3) and nuclear factor $\kappa \mathrm{B}$ signaling in glioblastoma cancer stem cells regulates the notch pathway," The Journal of Biological Chemistry, vol. 288, no. 36, pp. 26167-26176, 2013.

[165] D. Widera, I. Mikenberg, B. Kaltschmidt, and C. Kaltschmidt, "Potential role of NF- $\kappa \mathrm{B}$ in adult neural stem cells: The underrated steersman?" International Journal of Developmental Neuroscience, vol. 24, no. 2-3, pp. 91-102, 2006.

[166] D. W. Lee, D. Ramakrishnan, J. Valenta, I. F. Parney, K. J. Bayless, and R. Sitcheran, "The NF- $\kappa$ B RelB protein is an oncogenic driver of mesenchymal glioma," PLoS ONE, vol. 8, no. 2, Article ID e57489, 2013.

[167] C. Sakalar, M. Yuruk, T. Kaya, M. Aytekin, S. Kuk, and H. Canatan, "Pronounced transcriptional regulation of apoptotic and TNF-NF-kappa-B signaling genes during the course of thymoquinone mediated apoptosis in HeLa cells," Molecular and Cellular Biochemistry, vol. 383, no. 1-2, pp. 243-251, 2013.

[168] L. Nogueira, P. Ruiz-Ontañon, A. Vazquez-Barquero et al., "Blockade of the NFkB pathway drives differentiating glioblastoma-initiating cells into senescence both in vitro and in vivo," Oncogene, vol. 30, no. 32, pp. 3537-3548, 2011.

[169] Q. Zheng, L. Han, Y. Dong et al., "JAK2/STAT3 targeted therapy suppresses tumor invasion via disruption of the EGFRvIII/ JAK2/STAT3 axis and associated focal adhesion in EGFRvIIIexpressing glioblastoma," Neuro-Oncology, vol. 16, no. 9, pp. 1229-1243, 2014.

[170] O. D. Stechishin, H. A. Luchman, Y. Ruan et al., "On-target JAK2/STAT3 inhibition slows disease progression in orthotopic xenografts of human glioblastoma brain tumor stem cells," Neuro-Oncology, vol. 15, no. 2, pp. 198-207, 2013.

[171] W.-Q. Zhu, J. Wang, X.-F. Guo, Z. Liu, and W.-G. Dong, "Thymoquinone inhibits proliferation in gastric cancer via the STAT3 pathway in vivo and in vitro," World Journal of Gastroenterology, vol. 22, no. 16, pp. 4149-4159, 2016.

[172] G. Badr, M. Mohany, and F. Abu-Tarboush, “Thymoquinone decreases F-actin polymerization and the proliferation of human multiple myeloma cells by suppressing STAT3 phosphorylation and Bcl2/Bcl-XL expression," Lipids in Health and Disease, vol. 10, p. 236, 2011.

[173] R. Demicheli, M. W. Retsky, W. J. M. Hrushesky, M. Baum, and I. D. Gukas, "The effects of surgery on tumor growth: A century of investigations," Annals of Oncology, vol. 19, no. 11, pp. 18211828, 2008.

[174] W. Ceelen, P. Pattyn, and M. Mareel, "Surgery, wound healing, and metastasis: recent insights and clinical implications," Critical Review in Oncology/Hematology, vol. 89, no. 1, pp. 16-26, 2014.

[175] W. P. Ceelen, S. Morris, P. Paraskeva, and P. Pattyn, "Surgical trauma, minimal residual disease and locoregional cancer recurrence.," Cancer Treatment and Research, vol. 134, pp. 5169, 2007.

[176] R. Abramovitch, M. Marikovsky, G. Meir, and M. Neeman, "Stimulation of tumour growth by wound-derived growth factors," British Journal of Cancer, vol. 79, no. 9-10, pp. 13921398, 1999.

[177] Y. Maniwa, M. Okada, N. Ishii, and K. Kiyooka, "Vascular Endothelial Growth Factor Increased by Pulmonary Surgery
Accelerates the Growth of Micrometastases in Metastatic Lung Cancer," Chest, vol. 114, no. 6, pp. 1668-1675, 1998.

[178] F. P. K. Wu, K. Hoekman, S. Meijer, and M. A. Cuesta, "VEGF and endostatin levels in wound fluid and plasma after breast surgery," Angiogenesis, vol. 6, no. 4, pp. 255-257, 2003.

[179] S. Rajput, B. N. P. Kumar, P. Banik, S. Parida, and M. Mandal, "Thymoquinone restores radiation-induced TGF- $\beta$ expression and abrogates EMT in chemoradiotherapy of breast cancer cells," Journal of Cellular Physiology, vol. 230, no. 3, pp. 620-629, 2015.

[180] T. Yi, S.-G. Cho, Z. Yi et al., “Thymoquinone inhibits tumor angiogenesis and tumor growth through suppressing AKT and extracellular signal-regulated kinase signaling pathways," Molecular Cancer Therapeutics, vol. 7, no. 7, pp. 1789-1796, 2008.

[181] I. Ahmad, K. M. Muneer, I. A. Tamimi, M. E. Chang, M. O. Ata, and N. Yusuf, "Thymoquinone suppresses metastasis of melanoma cells by inhibition of NLRP3 inflammasome," Toxicology and Applied Pharmacology, vol. 270, no. 1, pp. 70-76, 2013.

[182] J. Kundu, B. Y. Choi, C.-H. Jeong, J. K. Kundu, and K.-S. Chun, "Thymoquinone induces apoptosis in human colon cancer HCT116 cells through inactivation of STAT3 by blocking JAK2and Src-mediated phosphorylation of EGF receptor tyrosine kinase," Oncology Reports, vol. 32, no. 2, pp. 821-828, 2014.

[183] G. Badr, E. A. Lefevre, and M. Mohany, “Thymoquinone inhibits the CXCL12-induced chemotaxis of multiple myeloma cells and increases their susceptibility to fas-mediated apoptosis," PLoS ONE, vol. 6, no. 9, Article ID e23741, 2011.

[184] J. Kundu, D.-H. Kim, J. K. Kundu, and K.-S. Chun, “Thymoquinone induces heme oxygenase-1 expression in HaCaT cells via Nrf2/ARE activation: Akt and AMPK $\alpha$ as upstream targets," Food and Chemical Toxicology, vol. 65, pp. 18-26, 2014.

[185] M. D. Walker, T. A. Strike, and G. E. Sheline, "An analysis of dose-effect relationship in the radiotherapy of malignant gliomas," International Journal of Radiation Oncology Biology Physics, vol. 5, no. 10, pp. 1725-1731, 1979.

[186] G. Delaney, S. Jacob, C. Featherstone, and M. Barton, "The role of radiotherapy in cancer treatment: estimating optimal utilization from a review of evidence-based clinical guidelines," Cancer, vol. 104, no. 6, pp. 1129-1137, 2005.

[187] R. Baskar, J. Dai, N. Wenlong, R. Yeo, and K. Yeoh, "Biological response of cancer cells to radiation treatment," Frontiers in Molecular Biosciences, vol. 1, 2014.

[188] C. Krakstad and M. Chekenya, "Survival signalling and apoptosis resistance in glioblastomas: opportunities for targeted therapeutics," Molecular Cancer, vol. 9, article 135, 2010.

[189] K. Kaufmann and G. Thiel, "Epidermal growth factor and platelet-derived growth factor induce expression of Egr-1, a zinc finger transcription factor, in human malignant glioma cells," Journal of the Neurological Sciences, vol. 189, no. 1-2, pp. 83-91, 2001.

[190] B. Mukherjee, B. McEllin, C. V. Camacho et al., "EGFRvIII and DNA double-strand break repair: A molecular mechanism for radioresistance in glioblastoma," Cancer Research, vol. 69, no. 10, pp. 4252-4259, 2009.

[191] Z. N. Orhon, C. Uzal, M. Kanter, M. Erboga, and M. Demiroglu, "Protective effects of Nigella sativa on gamma radiationinduced jejunal mucosal damage in rats," Pathology - Research and Practice, vol. 212, no. 5, pp. 437-443, 2016.

[192] R. Velho-Pereira, A. Kumar, B. N. Pandey, K. P. Mishra, and A. G. Jagtap, "Radioprotection by macerated extract of Nigella 
sativa in normal tissues of fibrosarcoma bearing mice," Indian Journal of Pharmaceutical Sciences, vol. 74, no. 5, pp. 403-414, 2012.

[193] M. S. Guida, A. A. El-Aal, Y. Kafafy, S. F. Salama, B. M. Badr, and G. Badr, "Thymoquinone rescues T lymphocytes from gamma irradiation-induced apoptosis and exhaustion by modulating pro-inflammatory cytokine levels and PD-1, bax, and Bcl-2 signaling," Cellular Physiology and Biochemistry, vol. 38, no. 2, pp. 786-800, 2016.

[194] G. R. Stark and J. E. Darnell, “The JAK-STAT pathway at twenty," Immunity, vol. 36, no. 4, pp. 503-514, 2012.

[195] H. Yu, D. Pardoll, and R. Jove, "STATs in cancer inflammation and immunity: a leading role for STAT3," Nature Reviews Cancer, vol. 9, no. 11, pp. 798-809, 2009.

[196] Y. Xu, Z. Li, C. Zhang, S. Zhang, Y. Ji, and F. Chen, "Knockdown of PKCe Expression Inhibits Growth, Induces Apoptosis and Decreases Invasiveness of Human Glioma Cells Partially Through Stat3," Journal of Molecular Neuroscience, vol. 55, no. 1, pp. 21-31, 2014.

[197] M. H. Aziz, B. B. Hafeez, J. M. Sand et al., "Protein kinase Cvarepsilon mediates Stat3Ser727 phosphorylation, Stat3regulated gene expression, and cell invasion in various human cancer cell lines through integration with MAPK cascade (RAF1, MEK1/2, and ERK1/2)," Oncogene, vol. 29, no. 21, pp. 31003109, 2010.

[198] T. Peng, L. Zhou, L. Zuo, and Y. Luan, "MIR-506 functions as a tumor suppressor in glioma by targeting STAT3," Oncology Reports, vol. 35, no. 2, pp. 1057-1064, 2016.

[199] Ç. Şakalar, K. İzgi, B. İskender et al., “The combination of thymoquinone and paclitaxel shows anti-tumor activity through the interplay with apoptosis network in triple-negative breast cancer," Tumor Biology, vol. 37, no. 4, pp. 4467-4477, 2016.

[200] A. M. Schmitt, C. D. Crawley, S. Kang et al., "P50 (NF- $\kappa$ B1) is an effector protein in the cytotoxic response to DNA methylation damage," Molecular Cell, vol. 44, no. 5, pp. 785-796, 2011.

[201] G. R. Sareddy, K. Geeviman, C. Ramulu, and P. P. Babu, “The nonsteroidal anti-inflammatory drug celecoxib suppresses the growth and induces apoptosis of human glioblastoma cells via the NF- $\kappa$ B pathway," Journal of Neuro-Oncology, vol. 106, no. 1, pp. 99-109, 2012.

[202] K. M. Dhandapani, V. B. Mahesh, and D. W. Brann, "Curcumin suppresses growth and chemoresistance of human glioblastoma cells via AP-1 and $\mathrm{NF} \kappa \mathrm{B}$ transcription factors," Journal of Neurochemistry, vol. 102, no. 2, pp. 522-538, 2007.

[203] D. R. Premkumar, E. P. Jane, N. R. Agostino, J. D. Didomenico, and I. F. Pollack, "Bortezomib-induced sensitization of malignant human glioma cells to vorinostat-induced apoptosis depends on reactive oxygen species production, mitochondrial dysfunction, Noxa upregulation, Mcl-1 cleavage, and DNA damage," Molecular Carcinogenesis, vol. 52, no. 2, pp. 118-133, 2013.

[204] V. Cecarini, L. Quassinti, A. Di Blasio et al., "Effects of thymoquinone on isolated and cellular proteasomes," FEBS Journal, vol. 277, no. 9, pp. 2128-2141, 2010.

[205] K. Effenberger, S. Breyer, and R. Schobert, "Terpene conjugates of the Nigella sativa seed-oil constituent thymoquinone with enhanced efficacy in cancer cells," Chemistry \& Biodiversity, vol. 7, no. 1, pp. 129-139, 2010.

[206] G. M. Ganea, S. O. Fakayode, J. N. Losso, C. F. Van Nostrum, C. M. Sabliov, and I. M. Warner, "Delivery of phytochemical thymoquinone using molecular micelle modified poly $(\mathrm{D}, \mathrm{L}$ lactide-co-glycolide) (PLGA) nanoparticles," Nanotechnology, vol. 21, no. 28, Article ID 285104, 2010.

[207] M. Elmowafy, A. Samy, M. A. Raslan et al., "Enhancement of bioavailability and pharmacodynamic effects of thymoquinone via nanostructured lipid carrier (NLC) formulation," AAPS PharmSciTech, vol. 17, no. 3, pp. 663-672, 2016.

[208] E. I. Salim and S. Fukushima, "Chemopreventive potential of volatile oil from black cumin (Nigella sativa L.) seeds against rat colon carcinogenesis," Nutrition and Cancer, vol. 45, no. 2, pp. 195-202, 2003.

[209] K. Takano, T. Kojima, T. Keira et al., "A novel drug delivery system for the human nasal epithelium," Advances in otorhinolaryngology, vol. 77, pp. 67-74, 2016. 


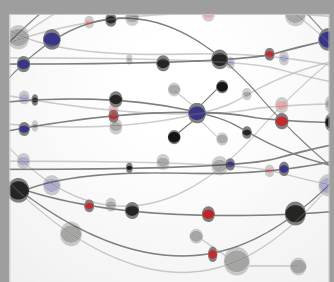

The Scientific World Journal
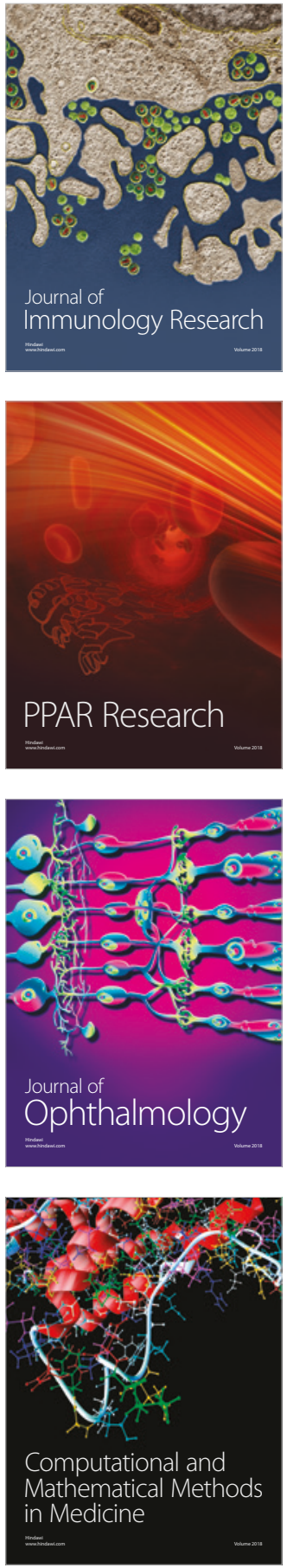

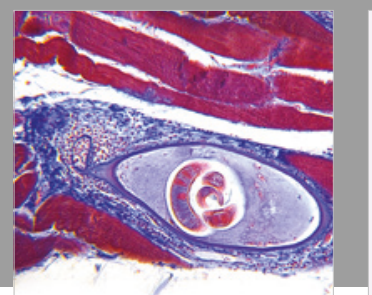

Gastroenterology Research and Practice

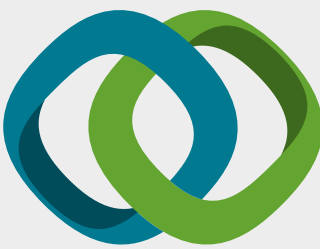

\section{Hindawi}

Submit your manuscripts at

www.hindawi.com
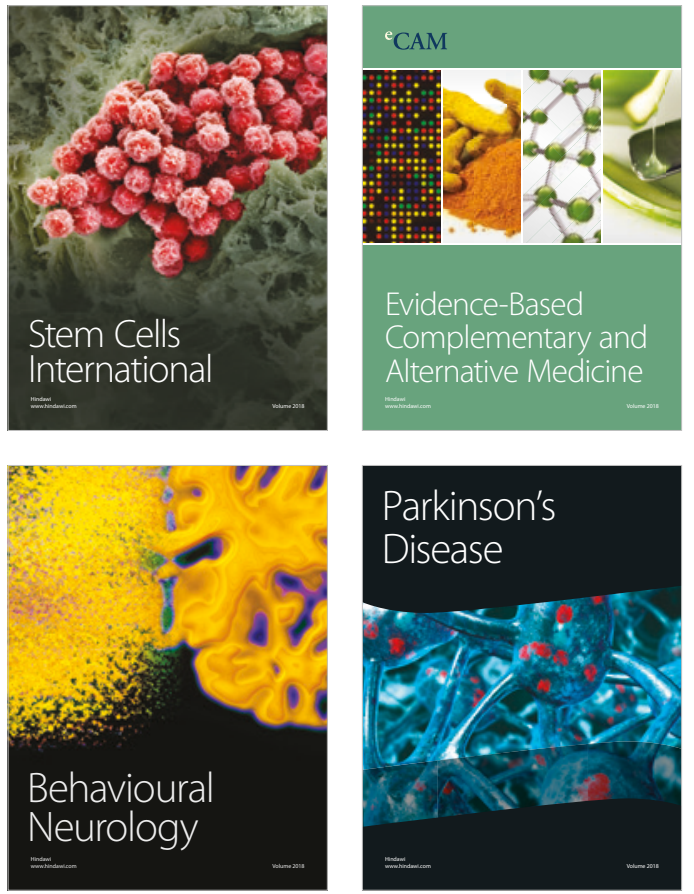

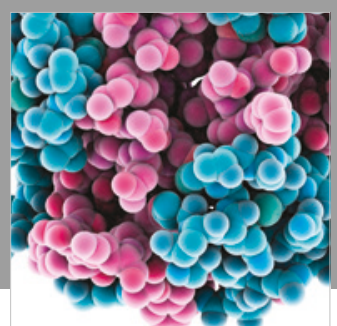

ournal of

Diabetes Research

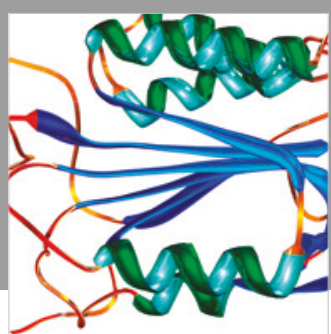

Disease Markers
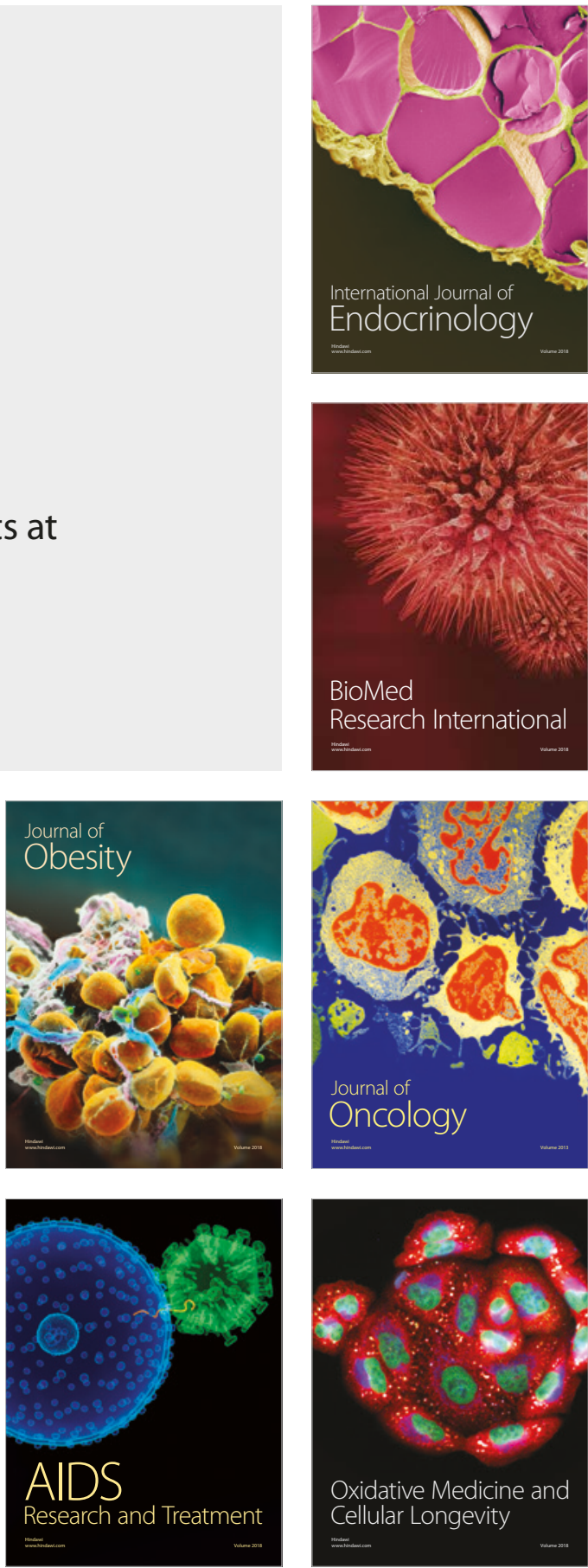